\title{
WestVirginiaUniversity
}

THE RESEARCH REPOSITORY @ WVU

Graduate Theses, Dissertations, and Problem Reports

2015

\section{Evaluation of Asphalt Mixture Performance Tester and Testing Protocol}

Kyle Turner

Follow this and additional works at: https://researchrepository.wvu.edu/etd

\section{Recommended Citation}

Turner, Kyle, "Evaluation of Asphalt Mixture Performance Tester and Testing Protocol" (2015). Graduate Theses, Dissertations, and Problem Reports. 6838.

https://researchrepository.wvu.edu/etd/6838

This Thesis is protected by copyright and/or related rights. It has been brought to you by the The Research Repository @ WVU with permission from the rights-holder(s). You are free to use this Thesis in any way that is permitted by the copyright and related rights legislation that applies to your use. For other uses you must obtain permission from the rights-holder(s) directly, unless additional rights are indicated by a Creative Commons license in the record and/ or on the work itself. This Thesis has been accepted for inclusion in WVU Graduate Theses, Dissertations, and Problem Reports collection by an authorized administrator of The Research Repository @ WVU. For more information, please contact researchrepository@mail.wvu.edu. 


\title{
Evaluation of Asphalt Mixture Performance Tester and Testing Protocol
}

\author{
Kyle Turner \\ Thesis submitted to the \\ at West Virginia University \\ Master of Science \\ in Civil Engineering \\ Dr. John P. Zaniewski, Chair \\ Dr. Avinash Unnikrishnan \\ Dr. Yoojung Yoon
}

Benjamin M. Statler College of Engineering and Mineral Resources

in partial fulfillment of the requirements for the degree of

Department of Civil and Environmental Engineering

Morgantown, West Virginia

2015

Keywords: Asphalt Mixture Performance Tester, Dynamic Modulus, Flow Number, Master Curves. 


\section{Abstract \\ Evaluation of Asphalt Mixture Performance Tester and Testing Protocol}

\section{Kyle Turner}

With the initial implementation of the Superpave mixture design method, no method "proof" testing the mixtures was included. This eventually led to the National Cooperative Highway Research Program (NCHRP) to sponsor projects that would eventually lead to the implementation of proof tests and a machine capable of performing these tests. The Asphalt Mixture Performance Tester (AMPT), which is capable of performing dynamic modulus $\left|\mathrm{E}^{*}\right|$ and flow number tests, was the product of these sponsored research projects.

The objective of this research was to set up the AMPT, establish a working procedure for preparing and testing specimens in the machine, demonstrate the machines capabilities by evaluating the relative performance of three binders, and evaluating testing protocols. Methods for preparing and testing specimens using the AMPT were refined throughout the setup of the machine prior to collection of data. Data collected using the AMPT was then evaluated and indicated that the machine was capable of producing data consistent with what was found in the literature review. Additionally, the performance a polymer modified PG 70-22 was found to be consistent with or slightly better than the unmodified version. Further analysis also indicated that dynamic modulus testing does not statistically affect the results of flow number testing, however the 4 hour oven aging time required for flow number testing does have a statistically significant effect. All statistical analysis were performed at a 0.05 significant level. 


\section{Acknowledgments}

I would like to thank my advisor Dr. Zaniewski for providing me with the opportunity to continue my education with a Master of Science degree. Without his guidance and encouragement I would not be in the position that I am in today.

To Dr. Avinash Unnikrishnan and Dr. Yoojung Yoon, thank you for reviewing my work and being on my committee

I would like to thank my parents for their continued and unwavering support throughout my college education.

To my the members of my lab group, Lara, Justin, Frank, and Hadi, thank you for your time and assistance with this research project.

A special thanks to my colleagues and friends at GeoStructures, Inc. for their patience and support during this research project. 


\section{Table of Contents}

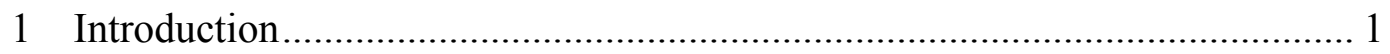

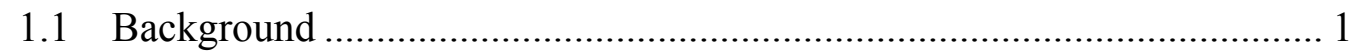

1.2 Problem Statement ............................................................................. 1

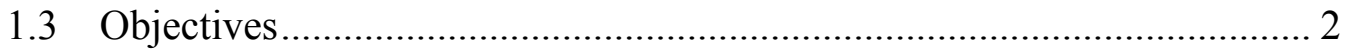

1.4 Scope and Limitations ..................................................................... 2

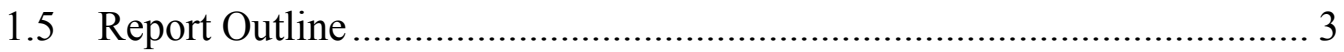

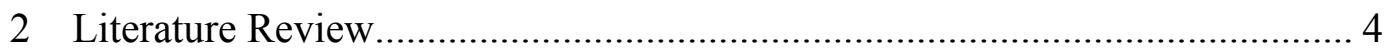

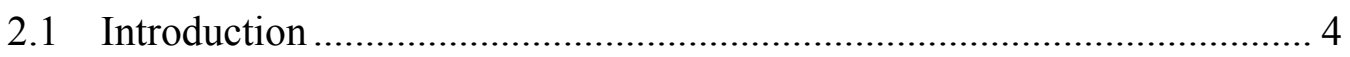

2.2 Dynamic Modulus and Phase Angle ......................................................... 4

2.3 Dynamic Modulus Master Curves......................................................... 10

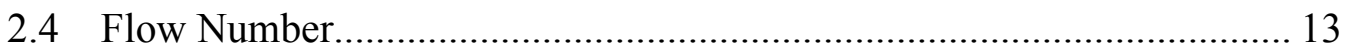

2.5 Specimen Preparation............................................................................. 17

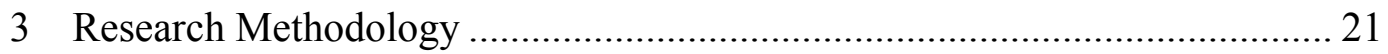

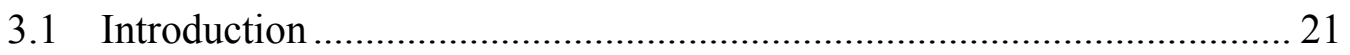

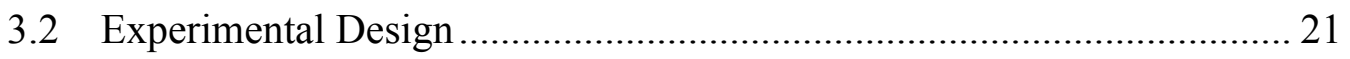

3.3 Design Binder Content ....................................................................... 22

3.4 Test Specimen Preparation..................................................................... 23

3.5 Dynamic Modulus Testing ................................................................ 24

3.6 Flow Number Testing........................................................................ 25

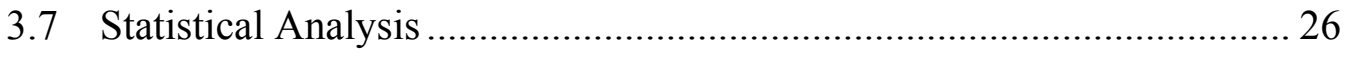

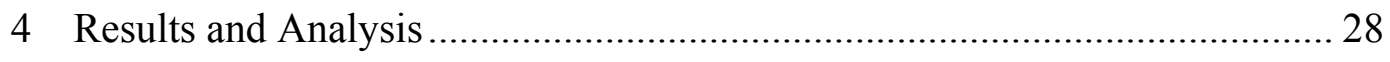

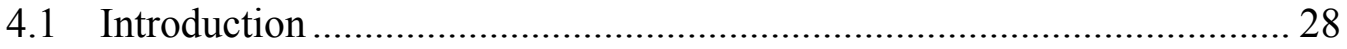

4.2 Dynamic Modulus and Phase Angle Results .......................................... 28

4.3 Dynamic Modulus Master Curves.......................................................... 32

4.4 Flow Number Results........................................................................ 36

4.5 Statistical Analysis .................................................................................. 39

5 Conclusions and Recommendations ……………….................................... 43

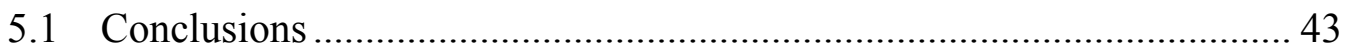

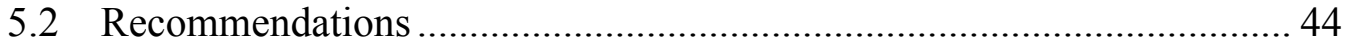




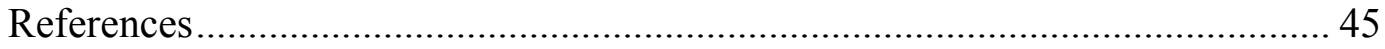

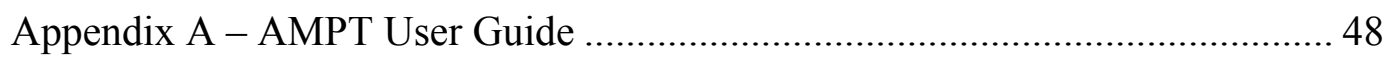

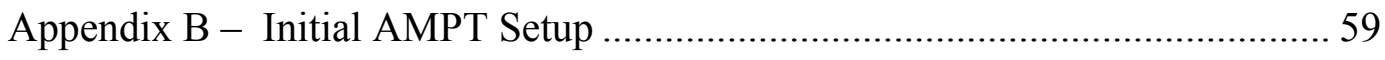

Appendix C - Dynamic Modulus Test Data...................................................... 66

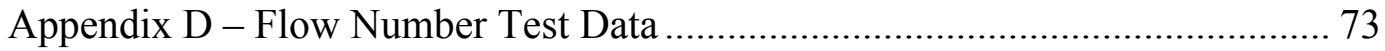




\section{Table of Figures}

Figure1-Dynamic Modulus Stress and Strain vs. Time........................................ 5

Figure 2-Dynamic Modulus (top) and Phase Angle (bottom) vs. Temperature ..... 8

Figure 3-Dynamic Modulus (top) and Phase Angle (bottom) vs. Frequency......... 9

Figure 4-Typical results for complex modulus test .............................................. 11

Figure 5-Flow Number Setup, Loading Stress, and Deformation ........................ 14

Figure 6-Accumulated Strain vs. Loading Cycle.................................................... 14

Figure7-12.5 NMAS Average Dynamic Modulus................................................ 18

Figure 8-Dynamic Modulus vs. Temperature …………...................................... 30

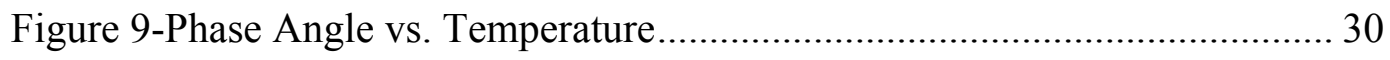

Figure 10-Dynamic Modulus vs. Frequency ......................................................... 31

Figure 11-Phase Angle vs. Frequency …………………....................................... 31

Figure 12-9.5 NMAS Dynamic Modulus Master Curves ....................................... 35

Figure 13-12.5 NMAS Dynamic Modulus Master Curves ...................................... 35

Figure 14-AMPT Test Specimen Information Sheet ............................................. 58

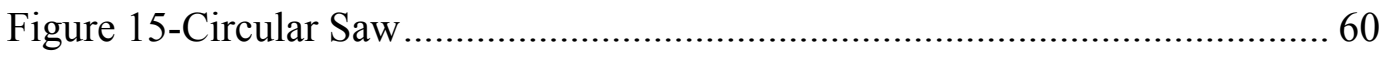

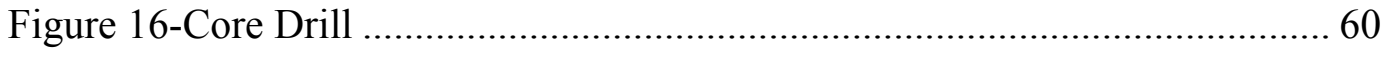

Figure 17-Test Specimen with Chipped End ..................................................... 62

Figure 18-Temperature Control Unit and Refrigerator........................................... 64

Figure 19-Test Specimen with Thermometer Probe Inserted ................................. 65

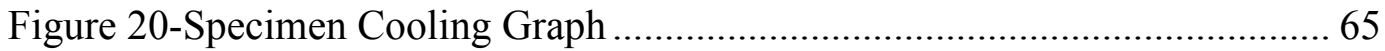




\section{Table of Tables}

Table 1-Flow Number Testing Parameters ......................................................... 16

Table 2-Minimum Average Flow Number Requirements ...................................... 16

Table 3-Literature Review Air Void Contents..................................................... 19

Table 4-Experimental Design Variables ............................................................. 22

Table 5-Mixture Volumetric Properties............................................................ 23

Table 6-12.5 NMAS PG 70-22 PM Averaged Dynamic Modulus and Phase Angle

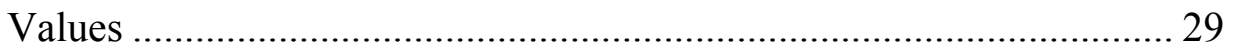

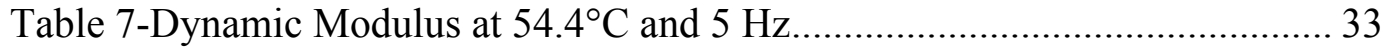

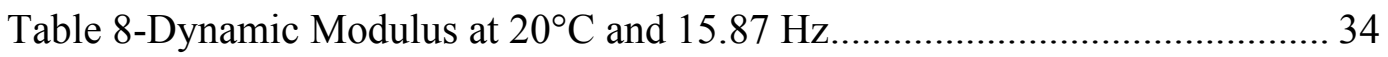

Table 9-Master Curve Beta Estimation Parameter .................................................. 36

Table 10-9.5 NMAS Flow Number (n=1) Summary ............................................. 37

Table 11-12.5 NMAS Flow Number $(\mathrm{n}=1)$ Summary .......................................... 38

Table 12-9.5 NMAS Flow Number $(n=20)$ Summary .......................................... 38

Table 13-12.5 NMAS Flow Number $(\mathrm{n}=20)$ Summary ......................................... 38

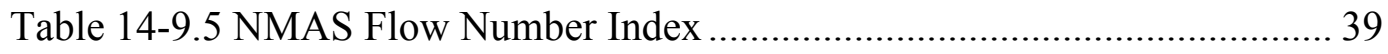

Table 15-12.5 NMAS Flow Number Index ....................................................... 39

Table 16-9.5 NMAS vs. 12.5 NMAS ANOVA Results ......................................... 40

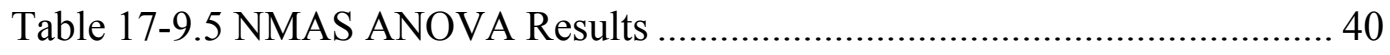

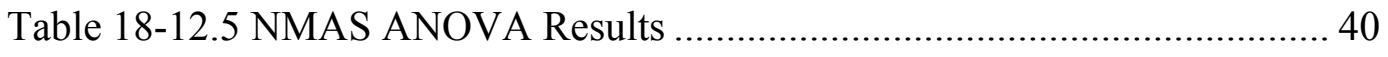

Table 19-9.5 NMAS Fisher LSD Test Comparison............................................... 41

Table 20-12.5 NMAS Fisher LSD Test Comparison............................................... 41

Table 21-9.5 NMAS Fisher LSD Binder Comparison............................................ 42

Table 22-12.5 NMAS Fisher LSD Binder Comparison.......................................... 42

Table 23-Test Specimen Dimensional Tolerances ............................................... 63

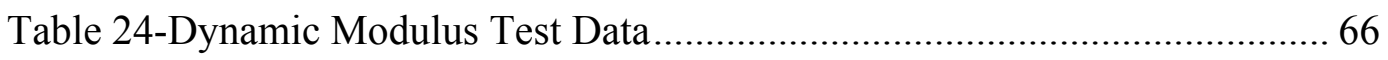

Table 25-Dynamic Modulus Test Specimen Data ................................................ 72

Table 26-Flow Number Test Data ..................................................................... 73 


\section{Introduction}

\subsection{Background}

As part of the Strategic Highway Research Program (SHRP), the Superpave methodology was developed for asphalt concrete volumetric mix design. While this method has proven to be effective, having been used for just over 20 years, there was no mechanical test to evaluate the quality of the mixes. Shortly after the completion of the Superpave mix design method, work was sponsored by the Federal Highway Administration (FHWA) and the National Cooperative Highway Research Program (NCHRP) to develop such "proof" tests. Three material properties were recommended for evaluating the performance of asphalt concrete mixtures. Dynamic modulus, $\left|E^{*}\right|$, was chosen for fatigue resistance and also to be used for mechanistic pavement design. Flow number, $\mathrm{F}_{\mathrm{n}}$, and Flow Time, $\mathrm{F}_{\mathrm{T}}$, where chosen to evaluate the rutting performance of a mix. Further research was performed to validate these parameters, while also working towards standardizing the testing methods and equipment (Bonaquist, 2008).

Equipment that met the specifications of the test method were produced by three companies, IPC Global, Interlaken Technology Corporation, and Medical Device Testing Services. Initially these devices were named Simple Performance Testers (SPT), however, in light of the complexity and cost of the devices equipment was renamed the Asphalt Mixture Performance Tester (AMPT). The FHWA sponsored a pooled fund project, TPF-5(178), for the implementation of the AMPT. Instrotek, the vendor for the IPC Global device, won the contract to provide AMPT machines under the pooled fund study. In December 2013, the West Virginia Division of Highways (WVDOH) completed the purchase of the AMPT and assigned the unit to the Asphalt Technology Laboratory at West Virginia University (WVU). This thesis describes the implementation and evaluation of the AMPT and an initial research project to evaluate the effect of binder on the dynamic modulus and flow number for two mix types.

\subsection{Problem Statement}

The recent acquisition of an AMPT for use by the Asphalt Technology Program at West Virginia University created a need to ensure a solid foundation was set for future 
testing with the machine. This involved not only setting up the machine, but also evaluating the capability of the machine and the associated testing protocols. The utility of the AMPT for evaluating the performance parameters of asphalt mixtures was demonstrated by in an experiment that compared three binder types for two Superpave mix types.

\subsection{Objectives}

The objective of this research was to explore the capabilities of the recently acquired AMPT for the Asphalt Technology Laboratory. Accomplishing this objective required the completion of several tasks, such as:

- Properly setting up the machine for testing.

- Compaction of samples.

- Ensuring the Saw and Corer produced acceptable test specimens.

- Setting up auxiliary equipment for sample conditioning prior to testing.

- Demonstrate the capability of the machine by evaluating the relative performance of three binder types: a PG 70-22 without polymer modifiers, a PG 70-22 with polymer modification and a PG 76-22 modified binder for two Superpave mix types, 9.5 and $12.5 \mathrm{~mm}$.

- $\quad$ Testing protocol

- Outline specific methodology needed to determine dynamic modulus and flow number testing using the AASHTO TP 60-13, TP 61-13, and TP 7913.

- Evaluate the effect of oven aging time on flow test results. Compare flow number results for sample sets conditioned for two and four hours.

- Testing dynamic modulus and flow number using the same sample.

- $\quad$ Test specimen air void content.

\subsection{Scope and Limitations}

The equipment available within the Asphalt Technology Laboratory posed several limitations involving this research. The computer that was set up to run the AMPT only came with programs to run dynamic modulus and flow number installed. The software provided with the AMPT allows a user to create test to protocols. However, since the 
purpose of this research was to evaluate the capabilities of the recently acquired AMPT, the scope of the project was limited to using the software that controls the machine to perform the AASHTO protocol.

\subsection{Report Outline}

This report is divided into five chapters and four appendices. Chapter 1 consisted of background information, the problem statement, and the objectives of this research. In Chapter 2, a review of literature pertinent to this research is presented. Chapter 3 presents the methodology followed in the research. Chapter 4 presents the data obtained from testing and the associated analysis of the data. Finally, Chapter 5 presents conclusions based on the data along with recommendations based on these conclusions. 


\section{Literature Review}

\subsection{Introduction}

The AMPT was developed specifically to address the needs of evaluating Superpave mix designs and as a means to determine the asphalt concrete material properties needed for the Mechanistic-Empirical Pavement Design method. As part of the FHWA Pooled Fund study, an AMPT was delivered to and set up at WVU, ready to perform the two basic tests, dynamic modulus and flow number. These two tests can both provide a wealth of knowledge with respect to the expected performance of asphalt concrete mixtures. The following describes:

- summary of dynamic modulus and phase angle,

- use of dynamic modulus tests at different temperatures and test frequencies to determine a master curve of modulus and reduced frequency for the asphalt mixture

- theory of flow number testing

- AASHTO protocols for preparing samples and testing asphalt mixtures with the AMPT

\subsection{Dynamic Modulus and Phase Angle}

The methodologies for determining the mechanistic material properties asphalt concrete have been researched for decades. Viscoelastic materials require two material parameters to describe the mechanistic response of asphalt concrete, the dynamic modulus and the phase angle. Figure1 (Bonaquist, 2008) show the stress-strain relationship for a visco-elastic material, such as asphalt concrete. The first haversine curve represents the stress applied to the specimen. The second haversine curve, with a shift in time to the right, represents the strain experienced by the sample. (Note the left abscissa shows load, or stress, and the right abscissa shows strain. These axes are not scaled; the graph does not imply a relative magnitude of stresses and strains.) 


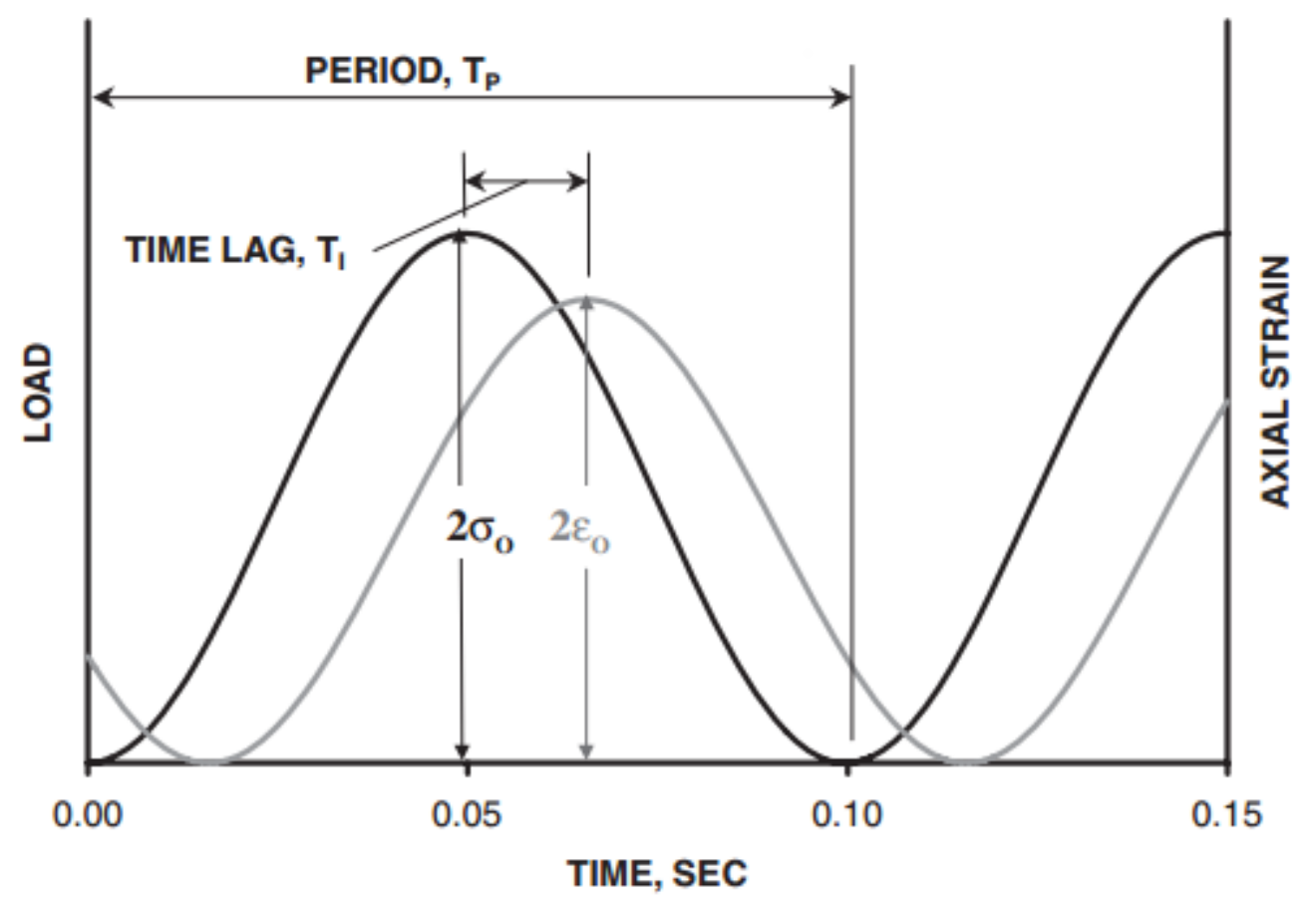

Figure1-Dynamic Modulus Stress and Strain vs. Time

The dynamic modulus, $\mathrm{E}^{*}$, as determined with the AMPT is:

$$
E^{*}=\frac{\sigma_{0}}{\epsilon_{0}}
$$

where:

$\sigma_{0}=$ peak (maximum) stress;

$\epsilon_{0}=$ peak (maximum) strain;

$\phi=$ phase angle (degrees);

$\omega=$ angular velocity (degrees/second);

$\mathrm{t}=$ time (seconds).

The phase angle, $\phi$, is:

$$
\phi=\frac{T_{i}}{T_{p}}
$$


where:

$\emptyset=$ angular velocity (degrees/second);

$\mathrm{T}_{\mathrm{i}}=$ time lag (seconds);

$\mathrm{T}_{\mathrm{p}}=$ period of the applied stress (seconds).

Pellinen and Witczak (2002) evaluated correlations of dynamic modulus, shear modulus, dynamic elastic modulus (obtained from wave propagation through a test specimen), and computed modulus factors from both dynamic and shear modulus values to field data from four different project locations. While the computed modulus value of $\left|E^{*}\right| / \sin ø$ at a temperature of $54.4^{\circ} \mathrm{C}$ and loading frequency of $5 \mathrm{~Hz}$ showed the highest correlation to the field data, it was determined that the computed value was only valid if the mixture was on the stiff side of the phase angle curve, where the value for phase angle is relatively low. Both dynamic and shear modulus showed similar effectiveness in predicting rutting trends in mixtures, with ultimately dynamic modulus being recommended due to its use with Mechanistic Empirical Pavement Design procedure. The final recommendation for evaluation of dynamic modulus was to compare the value of each mixture of at $54.4^{\circ} \mathrm{C}$ and a loading frequency of $5 \mathrm{~Hz}$, with higher modulus values indicating less of a potential for rutting to become a problem.

Testing on a specimen will result in one dynamic modulus and phase angle value per testing temperature and loading frequency. Li et. al. (2013) evaluated how testing temperature and loading frequency affected the dynamic modulus and phase angle of three different asphalt mixtures. Data was collected at five temperatures and ten loading frequencies in order to clearly establish the trends.

It was determined that as the testing temperature goes up, the dynamic modulus decreases when the frequency remains the same. One interesting point that was observed is that regardless of frequency, the dynamic modulus values all converged at about $55^{\circ} \mathrm{C}$. Phase angle however had no clear as a function of frequency. In general, the peak phase angle is below $25^{\circ} \mathrm{C}$ for frequencies 0.01 to $2 \mathrm{~Hz}$ and is around $45^{\circ} \mathrm{C}$ for frequencies 5 to $25 \mathrm{~Hz}$. The trends for dynamic modulus and phase angle values versus temperature are shown in Figure 2 (Li et. al., 2013). 
Frequency of loading had a different effect on the dynamic modulus than the temperature did. The trends for dynamic modulus and phase angle values versus frequency can be seen in Figure 3 (Li et. al., 2013). As the frequency of the loading was increased, the dynamic modulus increased. The rate of this increase however varied, with the dynamic modulus rapidly climbing as the frequencies increased across the lower values $(0.01$ to $5 \mathrm{~Hz})$ eventually leading to smaller increases across the higher frequency values ( 5 to $25 \mathrm{~Hz}$ ). The relationship between phase angle and loading frequency is slightly more complex. At $5^{\circ} \mathrm{C}$, the phase angle declines as the frequency increases. The phase angle at $15^{\circ} \mathrm{C}$ and $25^{\circ} \mathrm{C}$ increases at first, then decreases providing a discernable peak. Finally, at $45^{\circ} \mathrm{C}$ and $55^{\circ} \mathrm{C}$, the phase angle increases with the increase in frequency. All of these trends were indicated within all three of the mixtures that were tested. 

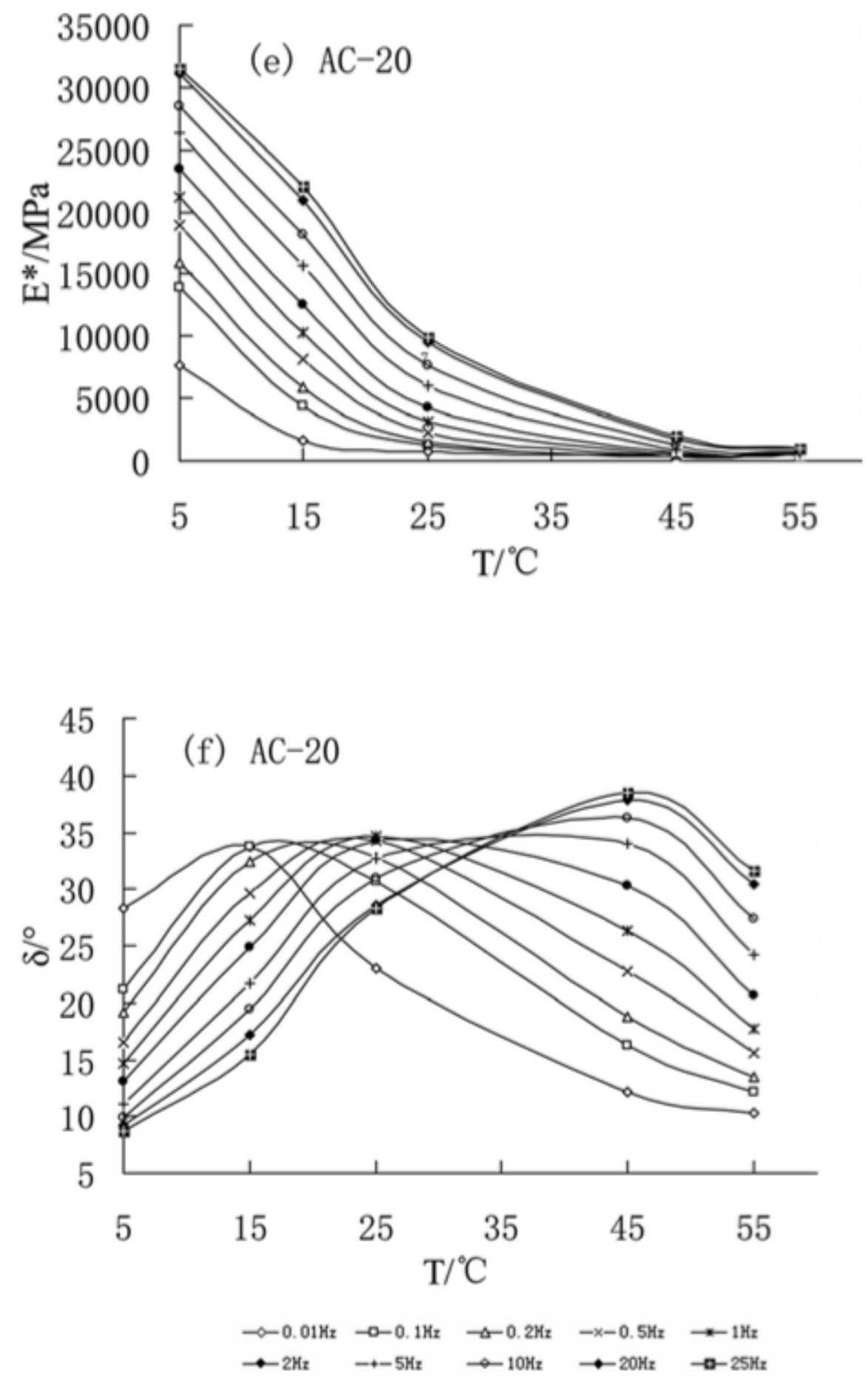

Figure 2-Dynamic Modulus (top) and Phase Angle (bottom) vs. Temperature 

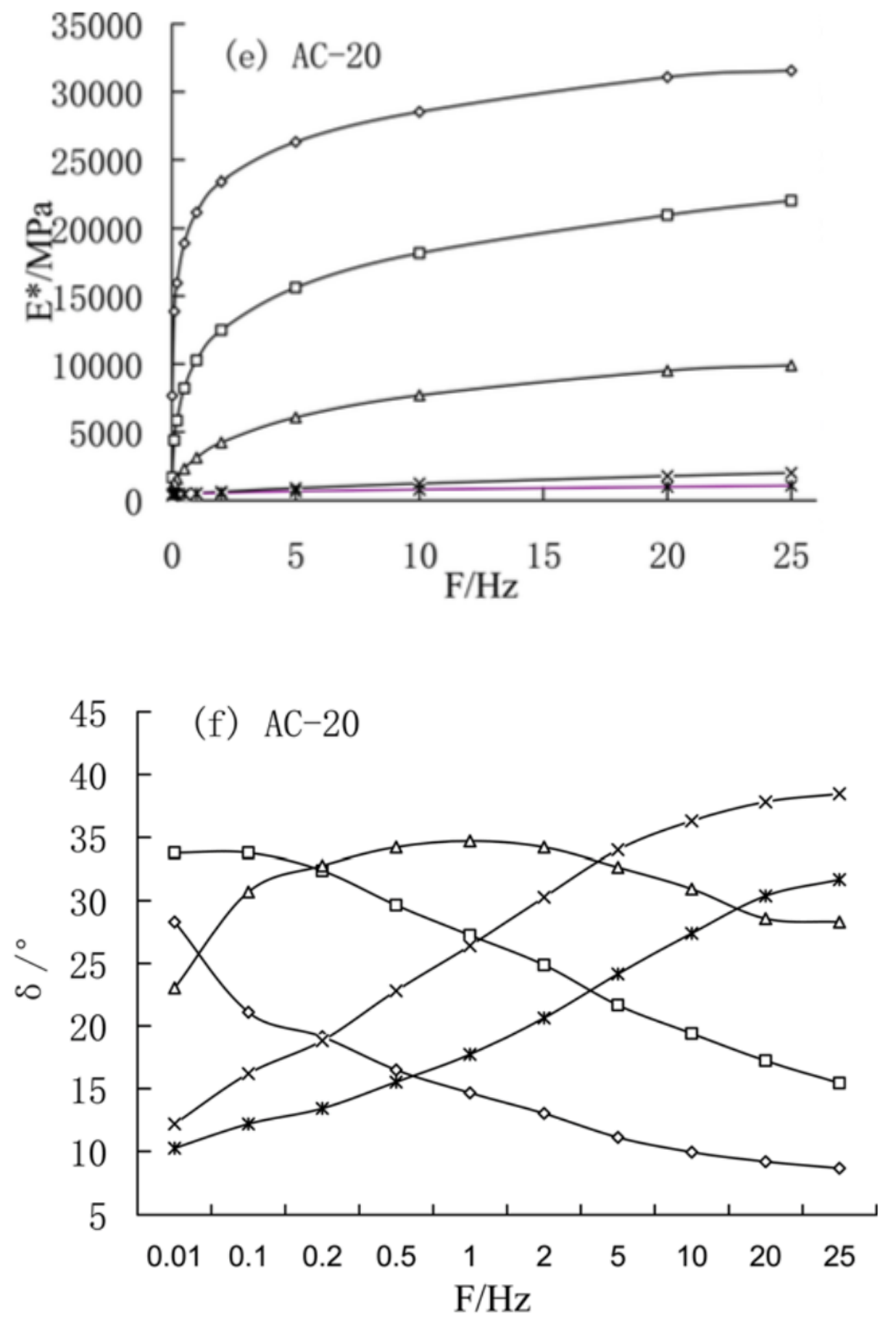

$\leadsto-5 \mathrm{C} \quad \square-15 \mathrm{C} \quad-25 \mathrm{C} \quad-\times-45 \mathrm{C} \rightarrow-55 \mathrm{C}$

Figure 3-Dynamic Modulus (top) and Phase Angle (bottom) vs. Frequency 


\subsection{Dynamic Modulus Master Curves}

Practical application of the dynamic modulus results must accommodate a range of temperatures and load frequencies. To accommodate this AASHTO PP 61-13 testing protocol specifies a range of temperatures and test frequencies for testing each specimen. Figure 4 shows dynamic modulus data for a temperature range of -20 to $54{ }^{\circ} \mathrm{C}$ and a frequency range of 0.01 to $30 \mathrm{~Hz}$ (Clyne et. al., 2003). The test results are the data points above and below the fitted line, and the points identified as " $x$ " on the fitted line. For the test data points, the abscissa is the actual test frequency. The frequencies and temperatures that can be used in a test are limited by the capability of the testing machine and by the ability of a sample to remain intact during the test, e.g. low frequency (long load duration) tests at high temperatures damage the specimen such that data could not be collected, but such a combination may exist in the field when a slow moving truck drives across a pavement on a hot day. Using analytical methods developed for the amorphous polymer industry (Williams et. al., 1955) the time-temperature superposition principle is used to resolve the array of test results into a single master curve, which illustrates the frequency effect on modulus at a chosen reference temperature. The frequency obtained through this analysis however is not an actual frequency. Once the shift has occurred it is defined as the reduced frequency since both the temperature and frequency of the original data points are taken into account (NCAT, 2014). As shown on Figure 4, test results at low temperatures are shifted to the right and have a reduced frequency that is greater than the test frequency. The converse is true for tests at high temperatures. The shift factor can be quantified using the Williams-Landel-Ferry equation:

$$
\log [\alpha(T)]=f\left(T, T_{r}\right)
$$

where:

$\alpha(T)=$ the sift factor at temperature $T$;

$f\left(T, T_{r}\right)=$ the function relating the reference temp. $\left(T_{r}\right)$ and test temp. (T). 
Various forms of the function between the test temperature and the reference temperature have been developed. The one that is included in AASHTO PP 61-13 is:

$$
\log [\alpha(T)]=\frac{\Delta E_{a}}{19.14714}\left(\frac{1}{T}-\frac{1}{T_{r}}\right)
$$

where:

$\Delta \mathrm{E}_{\mathrm{a}}=$ Activation Energy;

$\mathrm{T}=$ Test Temperature $(\mathrm{K})$;

$\mathrm{T}_{\mathrm{r}}=$ Reference Temperature $(\mathrm{K})$.

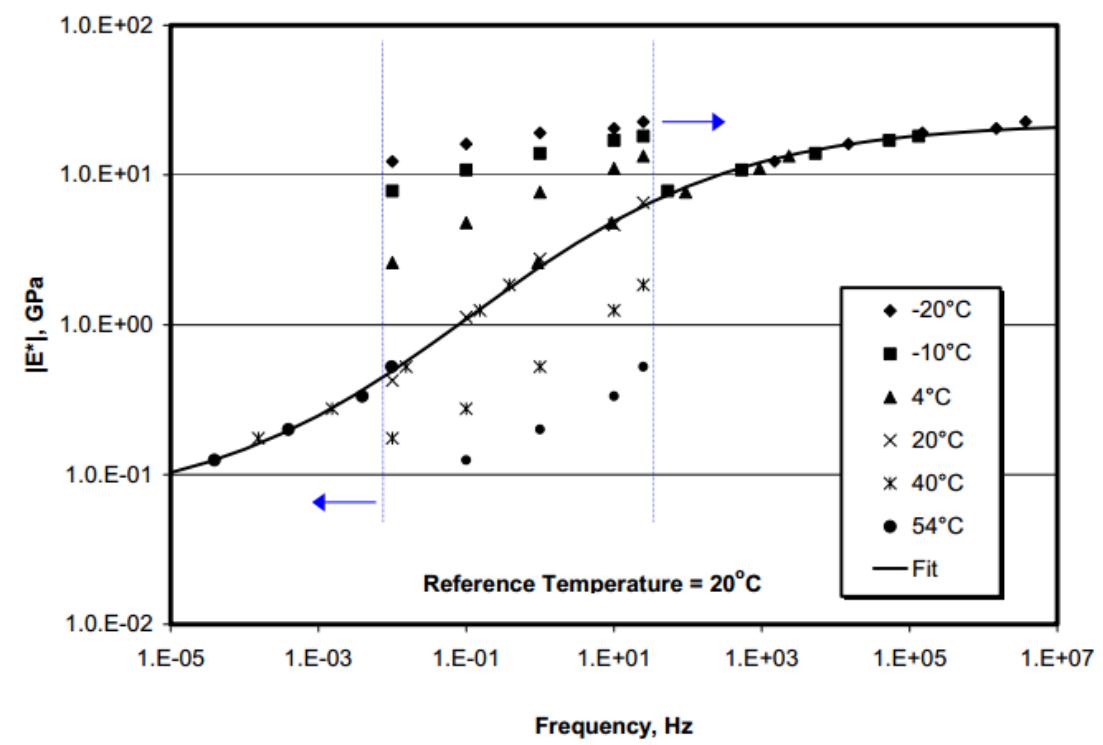

Figure 4-Typical results for complex modulus test

The reduced frequency for the master curve is determined as:

$$
\log \left(f_{r}\right)=\log (f)+\log [\alpha(T)]
$$

The functional form of the master curve used in AASHTO PP 61-13 is:

$$
\log |\mathrm{E}|=a+\frac{\mathrm{b}}{1+e^{\beta+\gamma\{\log [\alpha(T)]\}}}
$$


In this case, "a" would be the minimum modulus value and " $b$ " is the range of possible modulus values, i.e. $\mathrm{a}+\mathrm{b}$ is the maximum modulus value. The fraction of the range of the modulus values that is added to the minimum modulus value is controlled by the denominator.

In order to use the actual dynamic modulus equation listed in AASHTO PP 61-13, first the maximum limiting modulus must be estimated using the volumetric properties shown in the following equation, also found in AASHTO PP 61-13:

$$
\left|E^{*}\right|_{\text {max }}=P_{c}\left[4,200,000\left(1-\frac{V M A}{100}\right)+435,000\left(\frac{V F A \times V M A}{10,000}\right)+\frac{1-P_{C}}{\frac{\left(1-\frac{V M A}{100}\right)}{4,200,000}+\frac{V M A}{435,000(V F A)}}\right]
$$

where:

$$
P_{C}=\frac{\left(20+\frac{435,000(V F A)}{V M A}\right)^{0.58}}{650+\left(\frac{435,000(V F A)}{V M A}\right)^{0.58}}
$$

$\left|\mathrm{E}^{*}\right|_{\max }=$ the limiting maximum asphalt mixture dynamic modulus (psi);

$\mathrm{VMA}=$ the voids in the mineral aggregate (percent);

VFA=the voids filled with asphalt (percent).

Once the limiting maximum modulus is found, the following equation can then be used to generate the complete master curve:

$$
\log \left|\mathrm{E}^{*}\right|=\delta+\frac{\left(\left|E^{*}\right|_{\max }-\delta\right)}{1+e^{\beta+\gamma\left\{\log f+\frac{\Delta E a}{19.14714}\left[\frac{1}{T}-\frac{1}{T_{r}}\right]\right\}}}
$$

where:

$\left|\mathrm{E}^{*}\right|=$ Dynamic Modulus (psi);

$\delta, \beta$, and $\gamma=$ fitting parameters;

$\Delta \mathrm{E}_{\mathrm{a}}=$ Activation Energy (treated as a fitting parameter);

$\left|\mathrm{E}^{*}\right|_{\max }=$ the limiting maximum asphalt mixture dynamic modulus (psi);

$\mathrm{f}=$ loading frequency at test temperature $(\mathrm{Hz})$. 
The fitting parameters are estimated by fitting the experimental data to Equation 8. Bonaquist (2009) developed an Excel template, available through the FHWA website, to perform these calculations using the solver function. The net result of this process is a master curve of the complex modulus as a function of the reduced frequency at the reference temperature, as shown on Figure 4.

With the fitting parameters obtained, and using Equation 8, the dynamic modulus values for any loading frequency and temperature can be found. Dynamic modulus is estimated using the desired loading frequency and temperature into the Equation 8.

While the fitted parameters are useful in determining the modulus values at various loading frequencies and temperatures, they may be useful in evaluating differences in binder grades. Testing performed on various mixes in Utah over 5 years has provided a significant database. Roberts et. al. (2012) evaluated some of this data, while also looking at data from mixes tested in Wisconsin. They determined, through evaluating mixes with PG 70-28 and PG 64-34 binders, that the $\beta$ parameter showed the highest sensitivity in differentiating between the two binder grades.

\subsection{Flow Number}

Testing for flow number applies an axial compressive load for 0.1 seconds, followed by a 0.9 second resting period at a defined contact load. This process is repeated, with the accumulated, or permanent, strain being recorded at the end of every cycle. This loading produces a graph of deformations similar to that shown in the bottom of Figure 5 for a small segment of the test data.Results for an entire test would look similar to Figure 6 (Apeagyei and Diefenderfer, 2011). At the end of the resting period the permanent deformation is recorded, and the permanent strain calculated (Zhang et. al., 2013).

Figure 6 shows three distinct zones, primary, secondary, and tertiary deformation accumulation. The primary zone shows the, quick settlement upon initial loading, with a gradual decrease in the strain rate as more loads are applied. In the secondary zone, the accumulated strain is relatively linear. Finally, in the tertiary zone, the accumulated strain begins to rapidly increase with continued loading. Since the tertiary zone shows a rapid deterioration in the ability of the specimen to resist deformation due to loading, the 
inflection point on the graph between the secondary and tertiary zones is the flow number of the specimen.
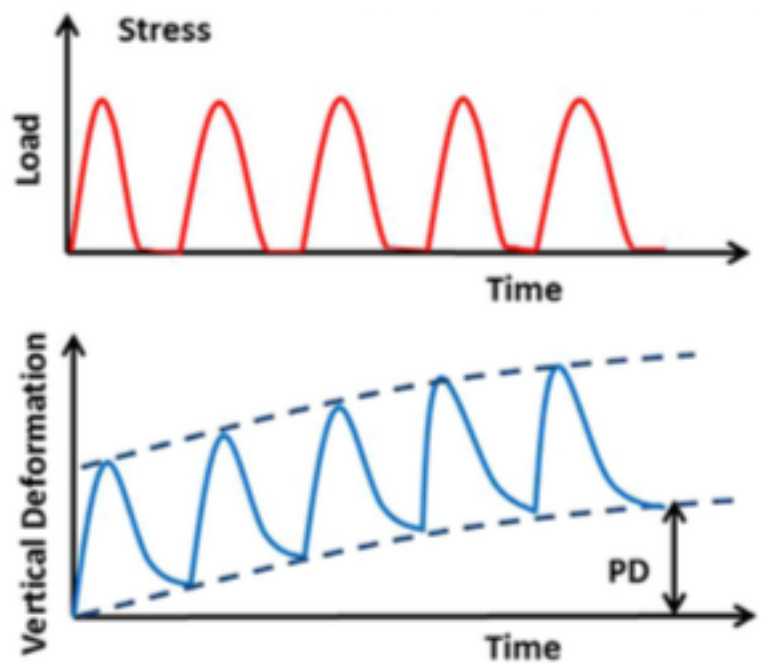

Figure 5-Flow Number Setup, Loading Stress, and Deformation

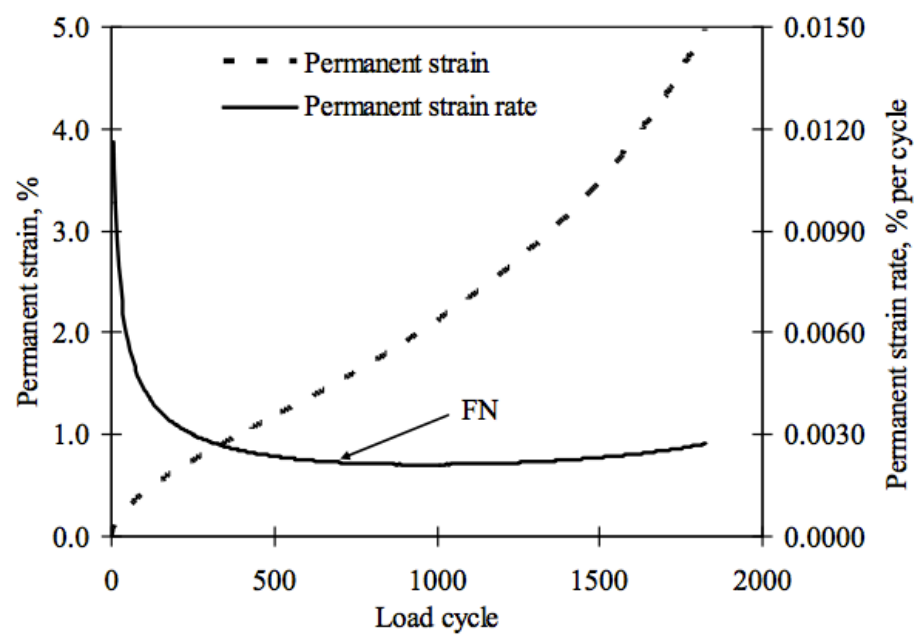

Figure 6-Accumulated Strain vs. Loading Cycle

A derivative curve, or strain rate curve represented by the solid line in Figure 6, is obtained through the use of either the Francken Model or a data smoothing technique to find the inflection point. The software provided with the AMPT for running the flow number test uses a data-smoothing model to obtain a flow number. In order to find the 
permanent strain rate with the data-smoothing model, the following equation is used (AASHTO TP79-13):

$$
\frac{d\left(\varepsilon_{p}\right)_{i}}{d N}=\frac{\left(\varepsilon_{p}\right)_{i+\Delta N}-\left(\varepsilon_{p}\right)_{i-\Delta N}}{2 \Delta N}
$$

where:

$\frac{d\left(\varepsilon_{p}\right)_{i}}{d N}=$ the rate of change of permanent axial strain at cycle $i$;

$\Delta \mathrm{N}=$ sampling interval;

$\left(\varepsilon_{\mathrm{p}}\right)_{\mathrm{i}+\Delta \mathrm{N}}=$ permanent strain at cycle $\mathrm{i}+\Delta \mathrm{N}$;

$\left(\varepsilon_{\mathrm{p}}\right)_{\mathrm{i}-\Delta \mathrm{N}}=$ permanent strain at cycle $\mathrm{i}-\Delta \mathrm{N}$.

Once the strain rate is obtained, the AMPT software then smooths the data by averaging the strain rate at the selected cycle with the two previous strain rates and the next two collected strain rates. Finally, the flow number is selected as the cycle where the lowest strain rate occurs. Should there be more than one cycle with the lowest recorded strain rate, the flow number is the first cycle at which the minimum strain rate occurs (Instrotek, 2011).

With the data-smoothing model, sudden spikes, or "noise" observed in the strain can easily influence the data smoothing done by the AMPT software, often caused by electrical noise on the LDVT signal. This noise can lead to erroneous flow number values and increased variability between data points from the same mixtures. By increasing the sample interval cycles, or $\Delta \mathrm{N}$ in Equation 9, the effects of this noise can be diminished however its effects are still present. With the software provided with the AMPT, a maximum value of 20 can be selected for $\Delta \mathrm{N}$, where the accumulated strain is analyzed at every $20^{\text {th }}$ cycle. Dongré et. al. (2009) points this problem out, while also noting that the flow number using the data smoothing technique analyzed on every $20^{\text {th }}$ cycle is within 20 cycles of the flow number found using the Francken model.

Appendix X2 in AASHTO TP 79-13 establishes a procedure for evaluating the rutting resistance of a mixture. Table 1 lists the test parameters set forth in the method. The adjusted PG temperature refers to the output obtained from LTPP Bind version 3.1 
(FHWA, 2015). The LTPP Bind parameters used to determine the adjusted temperature are:

- Desired reliability $50 \%$

- $\quad$ Target rut depth $-12.5 \mathrm{~mm}$

- $\quad$ Adjustment for traffic speed - 0

- Depth of layer

○ Surface $-20 \mathrm{~mm}$

Other layers - depth from surface to top of layer

Additionally, the loading conditions are shown in Table 1. Under the loading conditions specified, an impulse stress of $600 \mathrm{kPa}$ is applied to the specimen for the 0.1 second loading sequence. Once finished, a stress of $30 \mathrm{kPa}$ is applied to the specimen during the 0.9 second resting period. As the test is unconfined, i.e. the confining stress is zero.

Table 1-Flow Number Testing Parameters

\begin{tabular}{|c|c|}
\hline Test Parameter & Value \\
\hline Test Temperature & Adjusted PG Temperature \\
\hline Repeated Axial Stress & $600 \mathrm{kPa}$ \\
\hline Contact Stress & $30 \mathrm{kPa}$ \\
\hline Confining Stress & $0 \mathrm{kPa}$ \\
\hline
\end{tabular}

Table 2 presents the recommended criteria for determining if a mix is susceptible to rutting.

Table 2-Minimum Average Flow Number Requirements

\begin{tabular}{|c|c|}
\hline $\begin{array}{c}\text { Traffic Level } \\
\text { (million ESALs) }\end{array}$ & $\begin{array}{c}\text { HMA Minimum } \\
\text { Average } \\
\text { Flow Number }\end{array}$ \\
\hline$<3$ & --- \\
\hline 3 to $<10$ & 50 \\
\hline 10 to $<30$ & 190 \\
\hline$\geq 30$ & 740 \\
\hline
\end{tabular}


In addition to analysis for flow number, some research has investigated the idea of a flow number index. The flow number index is calculated by dividing the accumulated permanent strain observed at the flow number by the flow number. While there are no defined criteria for what would constitute a good mixture, a low value is representative of a mixture that is more resistant to rutting. This index showed stronger correlation to dynamic modulus values, particularly at higher temperatures, than the flow number data alone (Zhang et. al., 2013). The flow number index to replace the flow number as the preferred indicator of rutting susceptibility is still being evaluated.

\subsection{Specimen Preparation}

The protocol for preparing samples for testing with the AMPT are presented in AASHTO PP 60-13. This provisional practice describes the process for mixing, conditioning and compacting samples to be tested for both dynamic modulus and flow number. The Superpave gyratory compactor is used to compact samples to $180 \mathrm{~mm}$ tall by $150 \mathrm{~mm}$ in diameter. The samples are then trimmed to the required test dimensions by coring to a diameter of $100 \mathrm{~mm}$ with a tolerance of -2 to $+4 \mathrm{~mm}$. The diameter is measured at 4 locations and the standard deviation of these measurements is limited to $\leq 0.5 \mathrm{~mm}$. The length is trimmed to $150 \pm 2.5 \mathrm{~mm}$. The ends of the cylinder must be flat with a tolerance of $\leq 0.5 \mathrm{~mm}$. The sides of the cylinder must be perpendicular to the ends with a tolerance of $\leq 1.0 \mathrm{~mm}$. Per the terminology in AASHTO PP 60-13 samples that meet these criteria are called test specimens, and are ready for testing in the AMPT.

Protocols for performing dynamic modulus testing on the specimens with the AMPT is described in AASHTO TP 79-13; Procedure A is for dynamic modulus testing and Procedure B is for flow number testing. Both protocols include temperature conditioning of the specimens to bring the specimens to the testing temperature. No specific timeframe is given for the specimens to equilibrate to the testing temperature; however, the temperature of a dummy specimen with a temperature probe in the center must be carefully monitored to determine when testing can begin.

Per Appendix X2 of AASHTO TP 79-13, the air void content of test specimens for flow number is $7+/-0.5 \%$. The air void content of test specimens for dynamic modulus tests is not specified. In 2011, a study was performed on two plant produced 
Superpave mixtures, one $9.5 \mathrm{~mm}$ and one $12.5 \mathrm{~mm}$ Nominal Maximum Aggregate Size (NMAS), compacted to $88,91,94$, and $97 \%$ of the theoretical maximum specific gravity $\left(\mathrm{G}_{\mathrm{mm}}\right)$ to evaluate the effects of mixture density on stiffness, fatigue cracking, and rutting. Data from this testing determined that higher mixture bulk densities led to stiffer mixes in dynamic modulus testing, as shown by the dynamic modulus values in Figure7 (Mogawer et. al., 2011). It was also determined that higher mixture bulk densities resulted in mixtures that had lower rutting potential in flow number and Asphalt Pavement Analyzer (APA) testing.

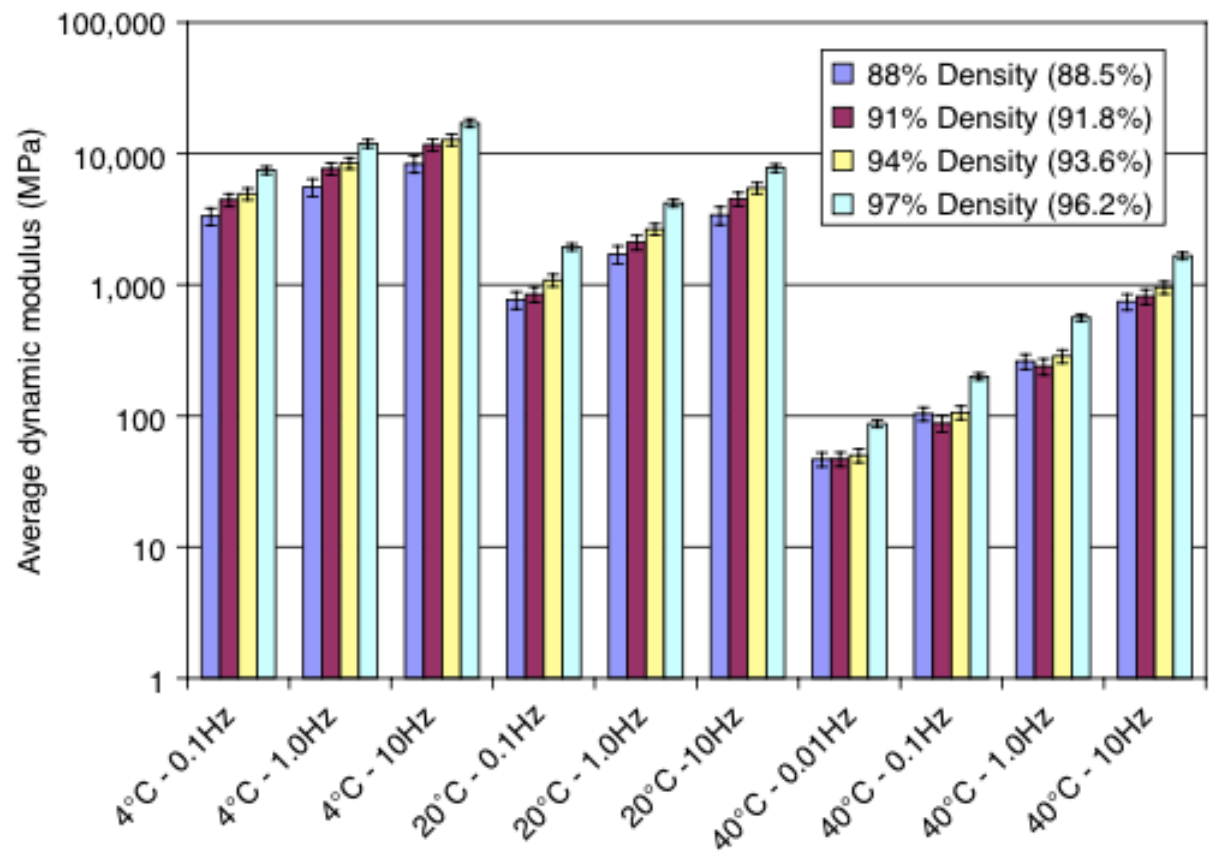

Figure7-12.5 NMAS Average Dynamic Modulus

In NCHRP Report 673 (Advanced Asphalt Technologies, 2011), it is

recommended that when evaluating rutting potential, the specimens should be prepared to the expected average field air void content. This results, primarily, in the use of two common values for the target air void content, $4 \%$, being the common mixture design air void content, and $7 \%$, being a common observed in place air void content. Table 3 provides a summary of the research referenced in this paper, listing the reference and a brief description of the air void effects used. While some of these references did not use the AMPT specifically, similar tests and testing methods were employed. This table is 
only intended to illustrate that with no standardization of the air void content for test specimens, there is little consistency within much of the collected test data.

Table 3-Literature Review Air Void Contents

\begin{tabular}{|l|l|}
\hline \multicolumn{1}{|c|}{ Article Reference } & Target Air Void Content \\
\hline Rowe et. al. 2009 & $2.3-11.3 \%$ in $1.5 \pm 0.3 \%$ increments \\
\hline Pellinen and Witczak 2002 & In-situ post construction air voids \\
\hline Li et. al. 2013 & 4\% Gyratory samples \\
\hline Diaz and Archilla 2013 & Varied, Data for high and low given. \\
\hline Roberts et. al. 2012 & Compacted to design of 100 Gyrations. \\
\hline Li et. al. 2014 & $4.0 \pm 0.5 \%$ \\
\hline Zhang et. al. 2013 & $7.0 \pm 1.0 \%$ \\
\hline Mogawer et. al. 2011 & $3.0,6.0,9.0,12.0 \%$ \\
\hline Bonaquist2011 & $7.0 \pm 0.5 \%$ \\
\hline Clyne et. al. 2003 & $\sim 5.0 \%$ \\
\hline
\end{tabular}

Bonaquist (2011), NCHRP Report 702, evaluated the precision of the AMPT. Prefabricated specimens and loose mix samples to be made into AMPT specimens were sent out to 8 laboratories with AMPT's, mostly consisting of seven IPC Global AMPT's and one Interlaken AMPT. Testing was performed at the 7\% air void content for both dynamic modulus and flow number. The conclusions and recommendations from this report resulted in precision statement tables for dynamic modulus and flow number testing. It was determined that compactor type, air void content, and specimen age had no systematic effect on the test results.

In addition, there is no delineation is made as to whether samples first tested for dynamic modulus can then be tested for flow number. Testing for dynamic modulus applies a loading pressure that returns an observed strain value between 75 and 125 micro-strains (AASHTO TP 79-13), however research performed by Rowe et.al. (2009) points out a potential for damage to occur during the testing for flow number.

Rowe et. al. (2009), evaluated the effects of air void content on dynamic modulus values, recommending that separate samples should be made for each test. During dynamic modulus testing at the high temperature $\left(40^{\circ} \mathrm{C}\right)$, significant strain developments were observed in the specimens. One specimen in particular showed a development of 600 micro-strains. Further analysis showed an error in the collected data, the cause of 
which is not known, and that the specimen likely developed closer to 1500 micro-strains. Based on this finding, the recommendation was made that samples tested for dynamic modulus should not be tested for flow number.

The testing performed by Rowe et. al. (2009) does not state what style of machine was used, however the dynamic modulus values collected for generation of a master curve were collected using AASHTO TP 60-03. This procedure, developed prior to the implementation of the AMPT, requires dynamic modulus values at three temperatures $\left(4^{\circ} \mathrm{C}, 20^{\circ} \mathrm{C}\right.$, and $\left.40^{\circ} \mathrm{C}\right)$ and nine frequencies $(25,20,10,5,2,1,0.5,0.2$, and $0.1 \mathrm{~Hz})$ for each specimen to develop the master curve. This is drastically different from the AMPT requirements to collect only 10 dynamic modulus values total, at the same temperature values, while reducing the frequencies needed to $10,1,0.1$ and $0.01 \mathrm{~Hz}$. 


\section{Research Methodology}

\subsection{Introduction}

An objective of this research was to establish a process for getting the AMPT operational. Considerable effort was applied to determining how the machine functions, establishing how to properly make and test specimens, and ensuring the AMPT produced reasonable results, in accordance with the literature review as well as meeting the data quality standards set forth in the testing protocols. With the AMPT being a relatively new machine, many of the testing protocols are in development and are published as provisional procedures. The specifications used for this study came from the AASHTO Standard Specifications, 2013 Edition; the most current edition available at the time of the testing. The protocols used in this research were:

- AASHTO PP60-13Preparation of Cylindrical Performance Test Specimens Using the Superpave Gyratory Compactor (SGC)

- AASHTO TP 79-13 Determining the Dynamic Modulus and Flow Number for Asphalt Mixtures Using the Asphalt Mixture Performance Tester (AMPT)

- AASHTO PP 61-13Developing Dynamic Modulus Master Curves for Asphalt Mixtures Using the Asphalt Mixture Performance Tester (AMPT)

\subsection{Experimental Design}

After setting up the AMPT and verifying that the equipment to be used in producing the specimens for testing could produce acceptable specimens, the experimental portion of the research began. Table 5 summarizes the types of samples evaluated during this research. The basic factorial included two mix types [9.5 and 12.5 mm NMAS] and three binder types [PG 70-22, PG 70-22 polymer modified, and PG 7622].

The for the mix designs in this research WVDOH specifications require determining the design binder content compacting the PG 70-22 samples with 80 gyrations and the PG 76-22 samples to 65 gyrations. The lower compaction effort used with the PG 76-22 binder is due to the polymer modification required for this binder 
under the WVDOH specifications. The PG 70-22 modified binder is a recently introduced product and the amount of modifier is less than is used in the PG 76-22 binder. Hence, it was decided to determine the optimum binder content for the PG 70-22 at both 65 and 80 gyrations and to test samples for dynamic modulus and flow number prepared at the two optimum binder contents.

Table 4-Experimental Design Variables

\begin{tabular}{|c|c|}
\hline Variable & Values \\
\hline NMAS & $9.5,12.5$ \\
\hline \multirow{2}{*}{ Binder Grade } & PG 70-22, PG 70-22 PM (80 Gyrations), \\
& PG 70-22 PM (65 Gyrations), PG 76-22 PM \\
\hline \multirow{3}{*}{ Testing Conditions } & Dynamic modulus and flow number (2 hour oven aging time), \\
& Flow number only (2 hour oven aging time) \\
& Flow number only (4 hour oven aging time) \\
\hline
\end{tabular}

Rowe et. al. (2009) found that samples used for dynamic modulus testing should not be used for flow number testing. However, the testing protocol they used was more extensive than AASHTO TP 79-13 and therefore, there was a greater potential for damaging the samples. Hence, it was decided to evaluate flow number for samples that were and were not subjected to the dynamic modulus test. If it can be shown that the results are equivalent then dynamic modulus samples can be tested for flow number, which saves the effort of preparing separate samples for each test.

Finally, the dynamic modulus and flow number should be sensitive to the asphalt film thickness. As asphalt ages binder is absorbed into the voids in the aggregate which reduces film thickness. This is simulated in the laboratory by aging the mixed samples in an oven prior to compacting. The standard oven aging time for volumetric mix design is 2 hours, with 4 hours being the standard for samples tested for mechanical properties. Flow number samples were prepared at both 2 and 4 hours of aging to see if the additional aging time influenced the results.

\subsection{Design Binder Content}

The samples for the dynamic modulus and flow number testing should be prepared at the design binder content for the aggregates used in the experiment. The contractor who provided the materials for the experiment also provided their mix design 
data. As a matter of practice the design binder content should be verified prior to preparing samples for the experiment.

Bulk specific gravity and maximum theoretical specific gravity samples were made at the design binder content from the job mix formula provided by the contractor. It was found that these samples did not meet the volumetric requirements of the WVDOH. Samples were made at different binder contents and a new design binder content was determined. The volumetric results are presented in Table 5. The binder contents in Table 5 were used for the test specimens for the AMPT testing. These mixture designs all produced samples that met the specifications called for by the West Virginia Department of Highways, with the exception of the 9.5 NMAS PG76-22 mixture having a Voids Filled with Asphalt of 73.1\% instead of the required 74\%, and the 12.5 NMAS PG76-22 mixture having a Voids in Mineral Aggregate of $14.4 \%$ instead of the minimum of $15 \%$ required.

Table 5-Mixture Volumetric Properties

\begin{tabular}{|c|c|c|c|c|c|c|c|}
\hline NMAS & Binder & Gyrations & $\mathrm{P}_{\mathrm{b}}$ & VTM & VMA & VFA & D/B \\
\hline 9.5 & PG 70-22 & 80 & 6.2 & 4.5 & 16.6 & 73.1 & 0.9 \\
\hline 9.5 & PG 70-22 PM & 80 & 6.2 & 3.4 & 16.4 & 79.1 & 0.9 \\
\hline 9.5 & PG 70-22 PM & 65 & 6.1 & 4.0 & 16.5 & 76.0 & 0.9 \\
\hline 9.5 & PG 76-22 PM & 65 & 5.9 & 4.0 & 16.2 & 76.0 & 0.9 \\
\hline 12.5 & PG 70-22 & 80 & 5.6 & 4.5 & 16.6 & 73.1 & 1.1 \\
\hline 12.5 & PG 70-22 PM & 80 & 5.4 & 4.0 & 14.8 & 73.0 & 1.2 \\
\hline 12.5 & PG 70-22 PM & 65 & 5.4 & 4.0 & 14.8 & 74.0 & 1.2 \\
\hline 12.5 & PG 76-22 PM & 65 & 5.2 & 4.0 & 14.4 & 73.0 & 1.2 \\
\hline
\end{tabular}

As the percent binder for the 65 and 80 gyration PG 70-22 PM 12.5 NMAS mixture were the same, those sample groups were combined and the number of samples for dynamic modulus testing were reduced.

The sequence for preparing and testing samples was randomized.

\subsection{Test Specimen Preparation}

The compaction protocol for preparing dynamic modulus and flow number samples requires compacting the samples to specified dimensions, $180 \mathrm{~mm}$ tall with a 
diameter of $150 \mathrm{~mm}$. The Superpave gyratory compactor will apply the number of gyration samples needed to achieve these dimensions. However, the samples, once trimmed to the testing dimensions, must also comply with a target air void content; $7 \pm 0.5 \%$ for this research. If samples do not meet the air void requirement a new sample is prepared and the amount of material placed in the mold is either increased to reduce air voids or decreased to increase air voids. Equation 11 from AASHTO PP 61-13 was used to estimate the initial mass. For all mixtures, a compaction height of $180 \mathrm{~mm}$ and an air void adjustment factor (F) of 1.0 for fine aggregates was used. After production of limited number of test specimens, the air void content of test specimens was taken and any further refinement to achieve the target air void content was done using Equation 12.

$$
\text { Mass }=\left[\frac{100-\left(V a_{t}+F\right)}{100}\right] * G_{m m} * 176.7147 * H
$$

where:

Mass $=$ estimated mass of the mixture needed $(\mathrm{g})$;

$\mathrm{Va}_{\mathrm{t}}=$ target air void content of the specimen (\%);

$\mathrm{G}_{\mathrm{mm}}=$ maximum specific gravity of the mixture;

$\mathrm{H}=$ height of gyratory compacted sample ( $\mathrm{mm})$;

$\mathrm{F}=$ air void adjustment factor.

$$
\operatorname{Mass}_{a d j}=\left[\frac{100-V a_{t}}{100-V a_{m}}\right] * \text { Mass }
$$

where:

Mass $_{\text {adj }}=$ adjusted sample mass needed (g);

$\mathrm{Va}_{\mathrm{t}}=$ target air void content of the specimen (\%);

$\mathrm{Va}_{\mathrm{m}}=$ measured trial test specimen air void content (\%);

Mass $=$ mass used to prepare the trial test specimen $(\mathrm{g})$.

\subsection{Dynamic Modulus Testing}

Prior to testing, samples were placed in the conditioning chambers overnight. A temperature probe in a dummy sample was used to verify that the samples were at the desired temperature prior to testing. Following the AASHTO TP 79-13 protocol, tests 
were first performed at the lowest testing temperature, $4^{\circ} \mathrm{C}$, followed by $20^{\circ} \mathrm{C}$ and lastly the high temperature, either $40^{\circ} \mathrm{C}$ for mixtures using the unmodified PG 70-22 and the modified PG 70-22 at 80 gyrations or $45^{\circ} \mathrm{C}$ for the PG 76-22 and the modified PG 70-22 at 65 gyrations. Careful attention was paid to ensure that the data being collected met the requirement listed in AASHTO TP 61-13 before the sample was tested at the next testing temperature, as the standard requires. The test frequencies were 10, 1, and $0.1 \mathrm{~Hz}$ for all three testing temperatures, with a frequency of $0.01 \mathrm{~Hz}$ tested at the high temperature for each mixture type.

For testing, TP 79-13 was followed with testing procedure listed under 9.4 of Procedure A for unconfined dynamic modulus testing. In compliance with this standard method, the distance between all three gauge point groupings was measured to ensure they met the $70 \pm 1 \mathrm{~mm}$ requirement. Teflon end friction reducers were used to reduce the friction between the both end platens and the specimen.

Upon completion of the test, the dynamic modulus and phase angle values were input into the master curve generator created by Bonaquist (2009). This excel sheet performs the time-temperature shift factors, by fitting a line to the shifted data allowing for the approximation of dynamic modulus values at any temperature and frequency.

\subsection{Flow Number Testing}

Flow number testing was performed in accordance with AASHTO TP 79-13. The testing temperature was determined using the LTTPBind software for a service reliability of $50 \%$. The five closest weather stations to the Morgantown area were selected since the aggregate was sourced locally. This analysis determined that testing for flow number should be conducted at $50.4^{\circ} \mathrm{C}$.

Similar to dynamic modulus testing, the test specimens must be brought to testing temperature prior to testing. As the temperature required the specimens to be heated up, the Yamato force draft ovens were used to condition the specimens and the dummy sample placed amongst the specimens to be tested to monitor the specimen temperatures. Double greased latex end friction reducers were placed between both ends of the specimen and the end platens in order to reduce the effects of friction. 


\subsection{Statistical Analysis}

Comparison of data collected in the flow number testing was done using a Fischer Least Significant Difference (LSD) test. This testing method can compare the various means of all possible factors by using the within mean square as an estimate for $\sigma^{2}$. One problem with this method is that the experiment-wise error rate is usually much higher than the comparison wise error rate. To work around this problem and help maintain control over the experiment-wise error rate, an Analysis of Variance (ANOVA) is first performed to compare all sample means and ensure that they are not equal. Should the ANOVA indicate the sample means are equal, no further analysis was conducted and the samples are all deemed to be statistically the same at to the selected significance level of 0.05 for the this research.

If the ANOVA rejects null hypothesis of equal means, further comparison of all sample means can continue. This comparison is done through the determination of the least significant difference using Equation 9 (Freund 2010):

$$
L S D=t_{\frac{\alpha}{2}} \sqrt{\frac{2 * M S W}{n}}
$$

where:

$t_{\frac{\alpha}{2}}=$ test statistic at significance level $\frac{\alpha}{2}$

$M S W=$ mean square within samples

$n=$ number of samples tested

The LSD value is compared to the difference between each sample pair. If the difference between these pairs is greater than the LSD value, the comparison is considered to be statistically significant at the determined significance level. Statistical analysis for this experiment looked to evaluate if the means between flow number sample groups were equal, at 0.05 significance level, in order to evaluate the differences between binder grades and testing methods.

To aid in the analysis of the data, StatPlus (AnalystSoft Inc.) was used. The program performs all the actions listed above. Should an ANOVA result in the finding 
that the means in a particular sample set are statistically similar, no further comparison result is shown. This aids the user in ensuring that the experiment wise error rate is minimized. 


\section{Results and Analysis}

\subsection{Introduction}

This chapter presents the results from testing and any corresponding analysis of the results. Since this is the first extensive use of the AMPT in the WVU Asphalt Technology Laboratory much of this section focuses on the various ways in which the data can be analyzed and presented. Appendix A is a summary of the test protocol followed and Appendix B describes the equipment set up and sample preparation procedures. A brief commentary on issues that affected data collection and quality are also included. Conclusions on which methods of analysis and presentation are the most effective and viable for future use will be discussed in the next section.

\subsection{Dynamic Modulus and Phase Angle Results}

Testing for dynamic modulus encountered no major problems, with only a few minor problems involving improper adhesion of the gauge points to the specimens. This problem resulted in the data not meeting the quality standards listed in TP 79-13 and was found to be the result of using to little adhesive epoxy. In one case, the gauge point even became detached from the specimen during testing. This problem was easily fixed by increasing the amount of adhesive being used, and all specimens that encountered this problem had the points remounted for retesting as necessary. Aside from this, no other problems were encountered during testing, and all data used in this research met the data quality standards previously mentioned.

The test results are included in Appendix C. Table 6provides an example of all of the averaged dynamic modulus and phase angle values for the 12.5 NMAS PG 70-22 PM. Figure 8 through Figure 11 illustrate the effects of temperature and frequency on dynamic modulus and phase angle for this same mixture. While the data collection from this experiment was not as extensive as that shown in the literature review, enough data was collected to be able to establish clear trends within the data.

All data for dynamic modulus and phase angle versus temperature and frequency in Appendix $\mathrm{C}$ exhibited the trends shown in Figure 8 through Figure 11, which represent the 12.5 NMAS PG 70-22 PM mixture, only with varying values for each binder grade 
and NMAS. Overall as the testing temperature increases, the dynamic modulus values decrease, at varying increments, and begin to converge. The phase angle versus temperature only has one noticeable peak, at $20^{\circ} \mathrm{C}$ on the $0.1 \mathrm{~Hz}$ curve, with the $1 \mathrm{~Hz}$ curve increasing with the appearance of a near peak value, and $10 \mathrm{~Hz}$ curve visibly continuing to increase. With only one value collected for the $0.01 \mathrm{~Hz}$ frequency, no trend could be seen.

Table 6-12.5 NMAS PG 70-22 PM Averaged Dynamic Modulus and Phase Angle Values

\begin{tabular}{|c|c|c|c|}
\hline $\begin{array}{c}\text { Testing } \\
\text { Temperature }\left({ }^{\circ}\right)\end{array}$ & $\begin{array}{c}\text { Testing } \\
\text { Frequency }(\mathrm{Hz})\end{array}$ & $\begin{array}{c}\text { Dynamic } \\
\text { Modulus }(\mathrm{ksi})\end{array}$ & Phase Angle $\left(^{\circ}\right)$ \\
\hline 4 & 0.1 & 866.5 & 8.5 \\
\hline 4 & 1 & 1276.0 & 8.0 \\
\hline 4 & 10 & 1710.3 & 7.4 \\
\hline 20 & 0.1 & 258.9 & 9.6 \\
\hline 20 & 1 & 511.0 & 9.2 \\
\hline 20 & 10 & 883.8 & 8.6 \\
\hline 45 & 0.01 & 18.5 & 6.8 \\
\hline 45 & 0.1 & 37.9 & 6.3 \\
\hline 45 & 1 & 87.9 & 5.9 \\
\hline 45 & 10 & 204.4 & 5.4 \\
\hline
\end{tabular}




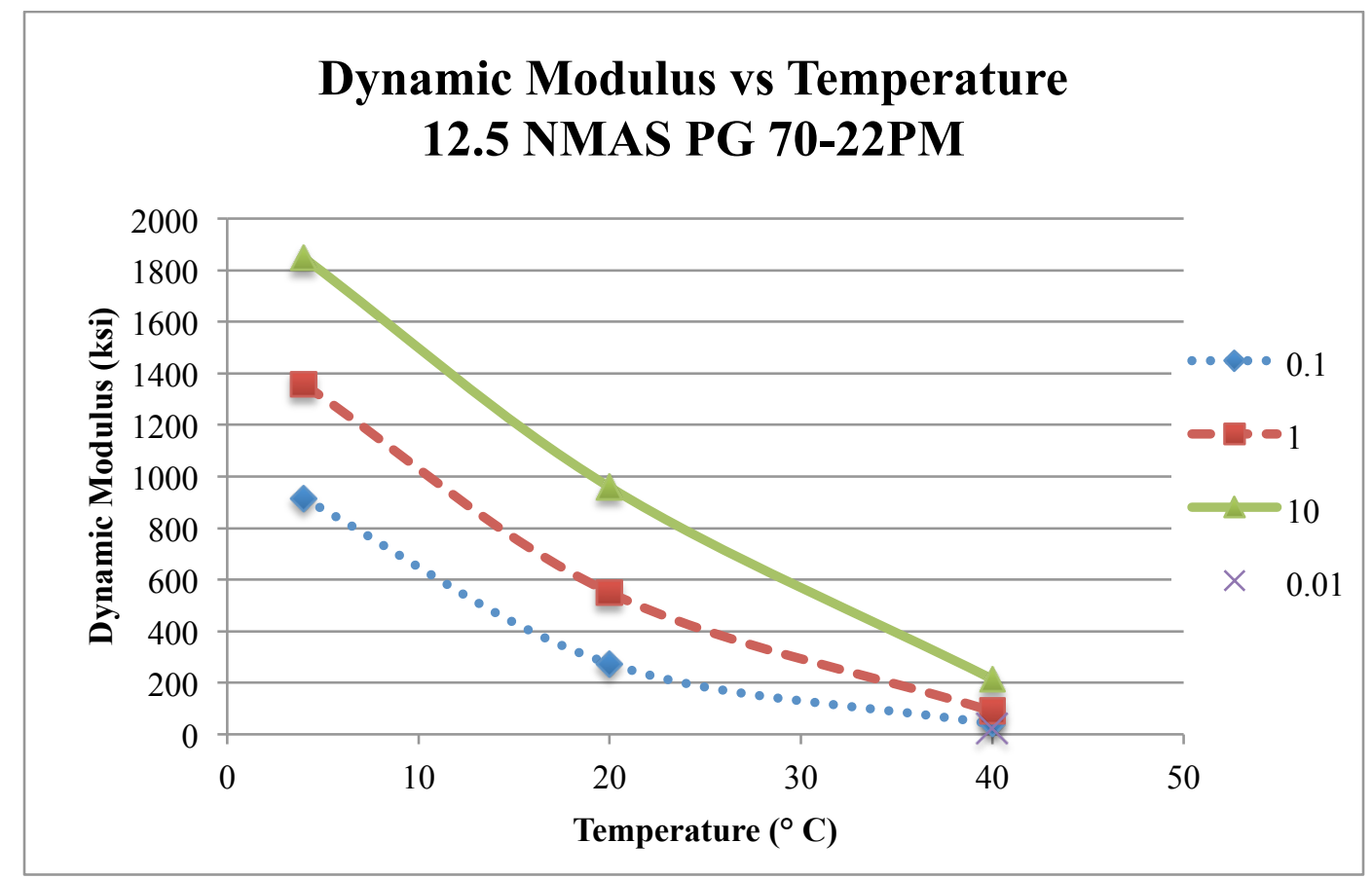

Figure 8-Dynamic Modulus vs. Temperature

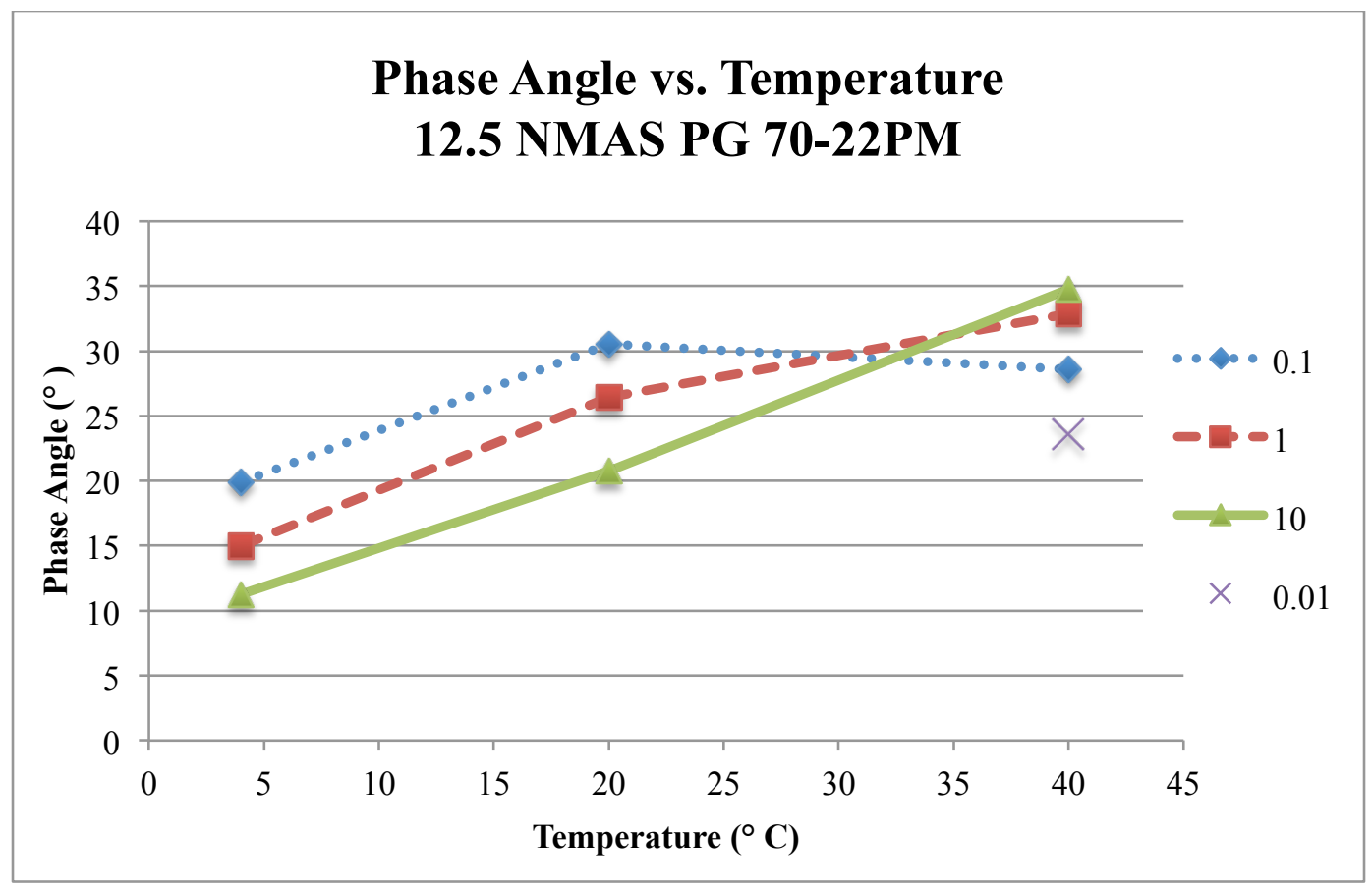

Figure 9-Phase Angle vs. Temperature 


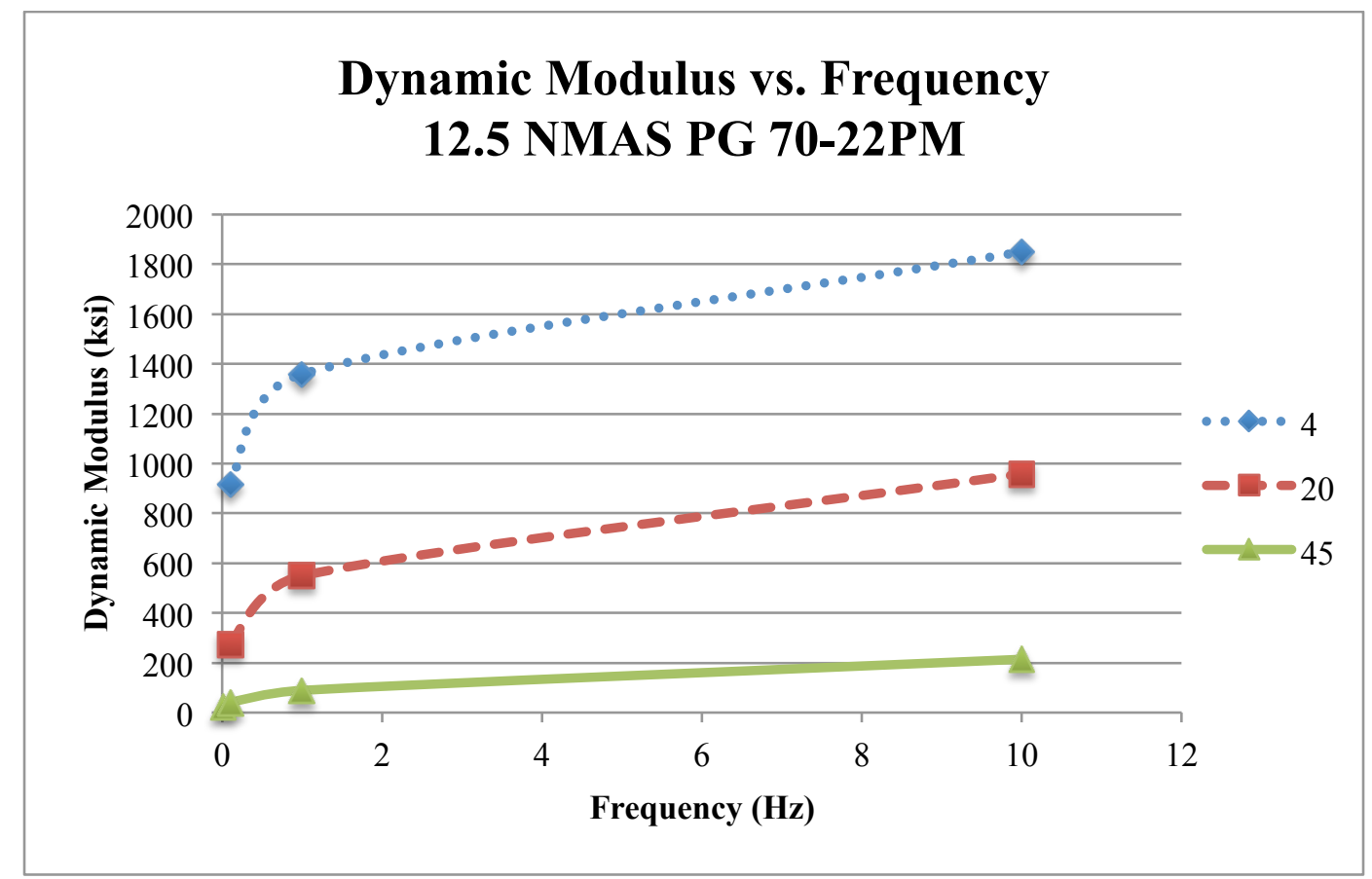

Figure 10-Dynamic Modulus vs. Frequency

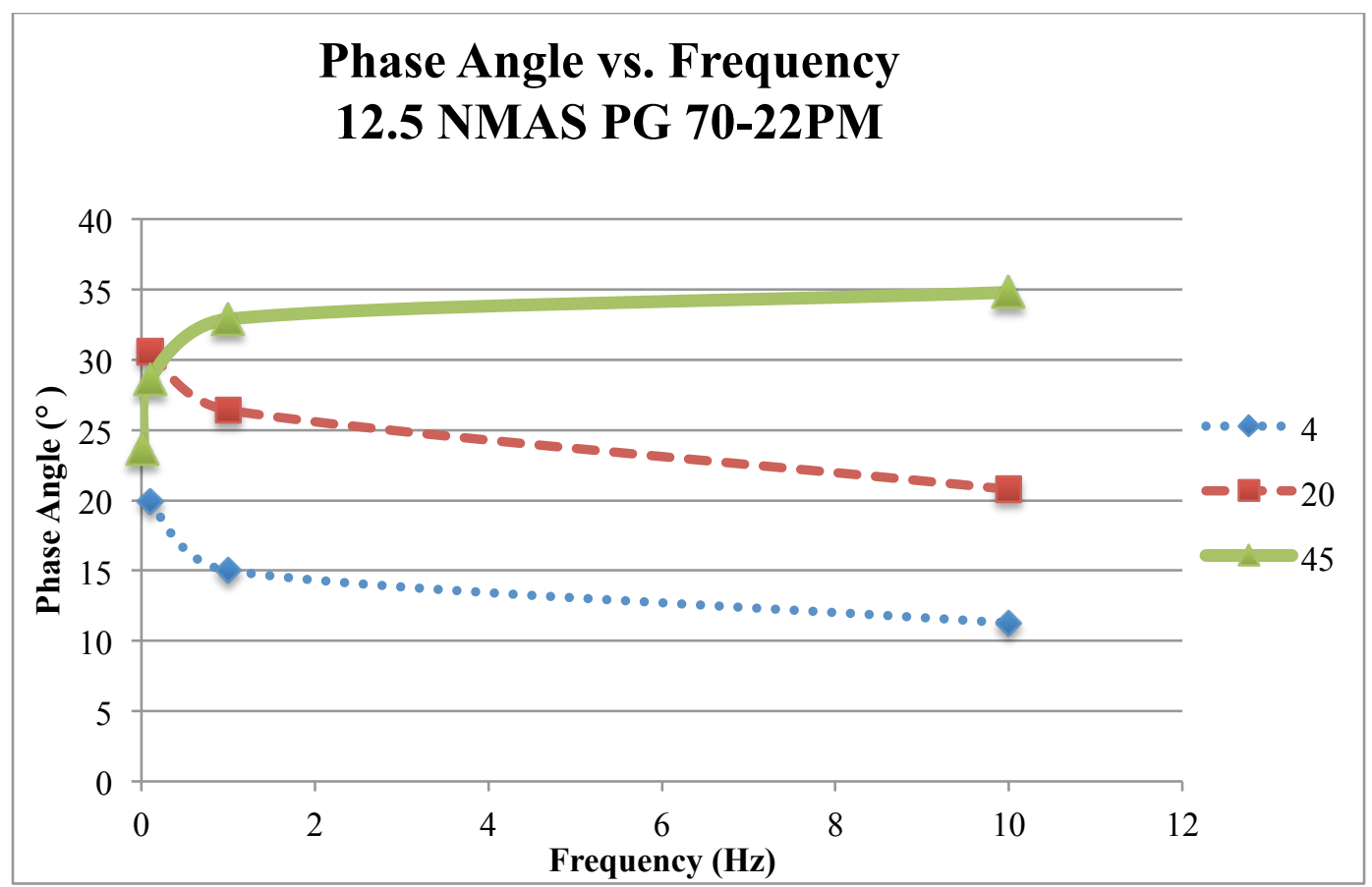

Figure 11-Phase Angle vs. Frequency 
In the dynamic modulus versus frequency graphs, all the values for dynamic modulus increase as the frequency increases. Based on these data, the dynamic modulus increases rapidly up to about $1 \mathrm{~Hz}$, and then the rate of change is lower up to $10 \mathrm{~Hz}$. The properties of the phase angle versus frequency graphs are similar, only with the 4 and $20^{\circ} \mathrm{C}$ curves decreasing instead of increasing like the $45^{\circ} \mathrm{C}$ curve. One thing worth noting is that the plateaus on the phase angle graphs are far more evident than on the dynamic modulus curves.

Overall, the trends described above are similar to those found through the literature review. While exact comparisons are difficult to make as the collected data in both this experiment and that shown in the literature review were collected at somewhat different points, only one clear variation is evident. The phase angle versus frequency graph depicted in Figure 11, does not show a gradual increase in the $45^{\circ} \mathrm{C}$ curve, as found by Li et. al. (2013) in the literature review.

\subsection{Dynamic Modulus Master Curves}

Upon completing the dynamic modulus testing, the data were input into the dynamic modulus master curve generator. Using the Excel solver feature, the master curves shown in Figure 12 and Figure 13 were generated, for a reference temperature of $20^{\circ} \mathrm{C}$. The trends depicted in the graph are those that were expected based on binder grade.

As the higher testing temperatures generate dynamic modulus values that are lower, the overall performance of each binder grade at the lower relative frequencies should be relative to their effective high temperature grade. This trend is shown in both figures, with the PG 70-22 unmodified having the lowest modulus values, the modified version with both 65 and 80 gyrations appearing slightly above, likely due to the modification of the binder, followed by the PG 76-22 having the highest modulus values. Also as expected, since all three binder grades have the same low temperature grade, the modulus values at the higher relative frequencies all appear to converge, having approximately the same modulus values.

As testing at the comparison temperature of $54.4^{\circ} \mathrm{C}$ and frequency of $5 \mathrm{~Hz}$ as recommended by Pellinen and Witczak (2002), is not specified in the procedures, the 
values were estimated using the master curves for the mixes. The data from these calculations are shown in Table 7, with the example calculations for the 9.5 NMAS PG 70-22 shown in Equations 14 through 18.

Table 7-Dynamic Modulus at $54.4^{\circ} \mathrm{C}$ and $5 \mathrm{~Hz}$

\begin{tabular}{|c|c|c|}
\hline Binder Grade & NMAS & $\begin{array}{c}\text { Estimated } \\
\text { Dynamic } \\
\text { Modulus (ksi) }\end{array}$ \\
\hline PG 70-22 & 9.5 & 46.9 \\
\hline PG 70-22 PM (80) & 9.5 & 38.4 \\
\hline PG 70-22 PM (65) & 9.5 & 44.0 \\
\hline PG 76-22 & 9.5 & 53.0 \\
\hline PG 70-22 & 12.5 & 55.7 \\
\hline PG 70-22 PM & 12.5 & 50.4 \\
\hline PG 76-22 & 12.5 & 61.8 \\
\hline
\end{tabular}

The data in Table 7 indicates the unmodified PG 70-22 binder would have better rutting performance than the modified PG 70-22 binder. This is counter intuitive and should be researched further.

In all cases the data indicated the $12.5 \mathrm{~mm}$ mixes would have less rutting sustibility than the $9.5 \mathrm{~mm}$ mixes, as would be expected.

Maximum modulus calculation:

$$
\begin{aligned}
P_{C}=\frac{\left(20+\frac{435,000(62.6)}{19.0}\right)^{0.58}}{650+\left(\frac{435,000(62.6}{19.0}\right)^{0.58}}=0.851 \\
\left|E^{*}\right|_{\max }=0.851\left[4,200,000\left(1-\frac{19.0}{100}\right)+435,000\left(\frac{62.6 \times 19.0}{10,000}\right)+\frac{1-0.851}{\frac{\left(1-\frac{19.0}{100}\right)}{4,200,000}+\frac{19.0}{435,000(62.6)}}\right] \\
\quad=3108.9 \mathrm{ksi}
\end{aligned}
$$

Shift factor calculation:

$$
\alpha(T)=\frac{201527.6}{19.14714}\left(\frac{1}{54.4+273.2}-\frac{1}{20+273.2}\right)=-3.769
$$


Reduced frequency calculation:

$$
\log \left(f_{r}\right)=\log (5)+(-3.769)=-3.070
$$

Dynamic modulus calculation:

$$
\mathrm{E}^{*}=10^{0.194+\frac{(\log (3108.9)-0.194)}{1+e^{-1.147+(-0.441)(-3.070\}}}}=47.1 k s i
$$

The dynamic modulus was also calculated from the master curves using a frequency of $15.87 \mathrm{~Hz}$ at $20^{\circ} \mathrm{C}$. This frequency was calculated by finding the approximate load duration for an 18 kip axle load with a tire pressure of $110 \mathrm{psi}$, traveling at $55 \mathrm{mph}$. The data from these dynamic modulus calculations is shown in Table 8, with trends that are consistent with the values shown in Table 7.

Table 8-Dynamic Modulus at $20^{\circ} \mathrm{C}$ and $15.87 \mathrm{~Hz}$

\begin{tabular}{|c|c|c|}
\hline Binder Grade & NMAS & $\begin{array}{c}\text { Estimated } \\
\text { Dynamic } \\
\text { Modulus (ksi) }\end{array}$ \\
\hline PG 70-22 & 9.5 & 938.8 \\
\hline PG 70-22 PM (80) & 9.5 & 869.5 \\
\hline PG 70-22 PM (65) & 9.5 & 850.1 \\
\hline PG 76-22 & 9.5 & 919.1 \\
\hline PG 70-22 & 12.5 & 1109.5 \\
\hline PG 70-22 PM & 12.5 & 1015.8 \\
\hline PG 76-22 & 12.5 & 1115.7 \\
\hline
\end{tabular}




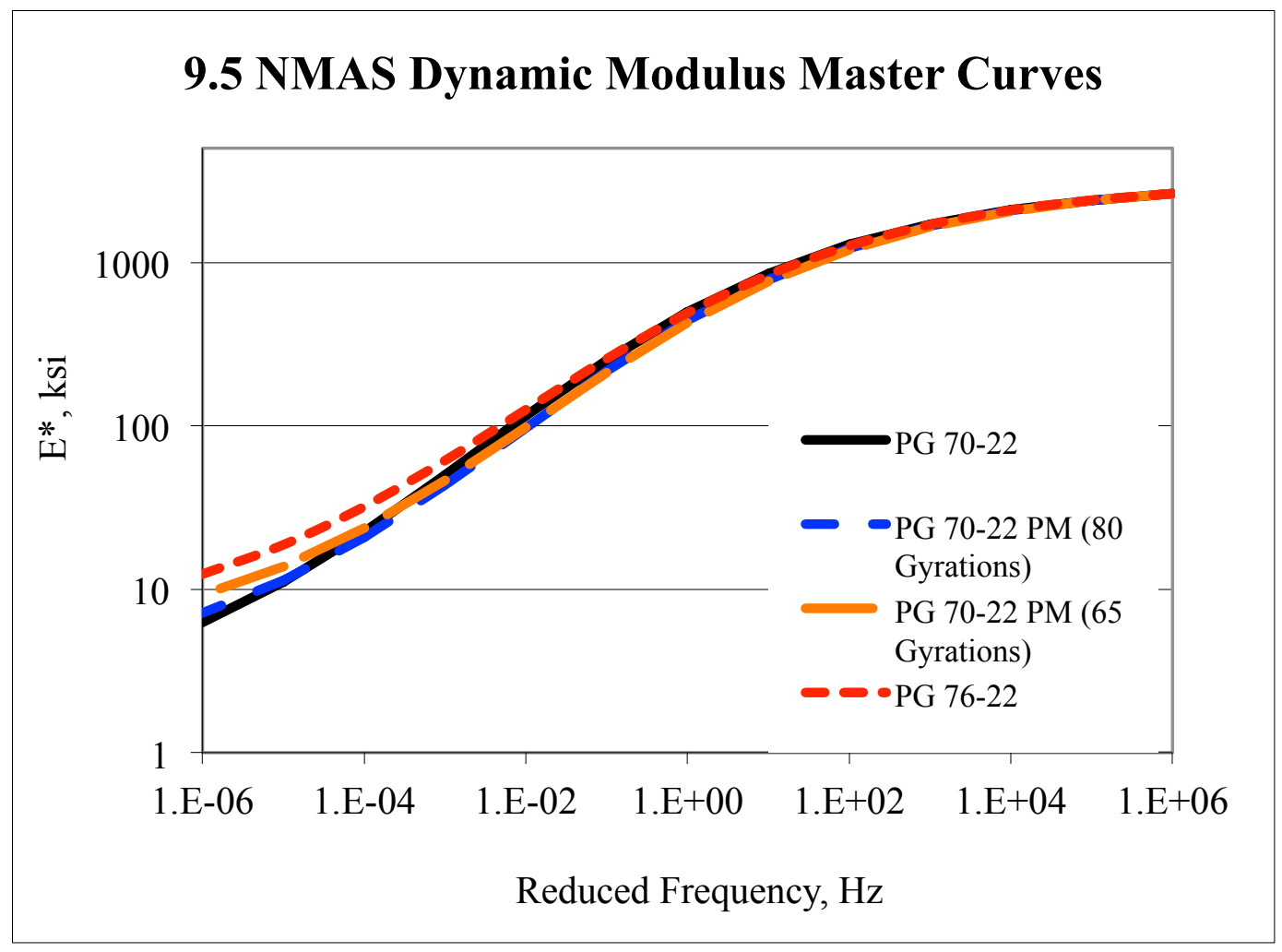

Figure 12-9.5 NMAS Dynamic Modulus Master Curves

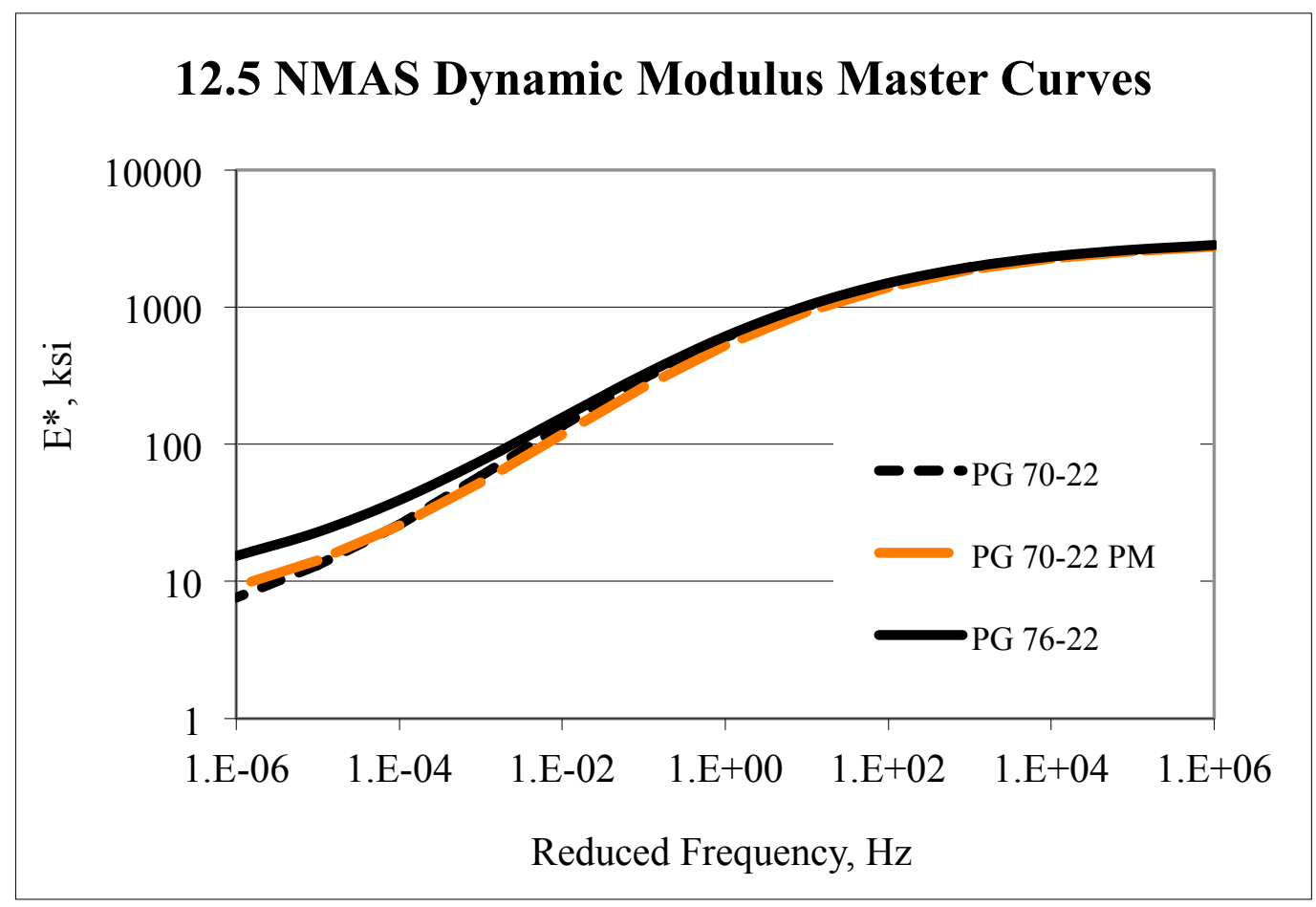

Figure 13-12.5 NMAS Dynamic Modulus Master Curves 
Based on the generation of the master curves, Table 9provides a summary of the beta parameters used in the master curve for each binder grade and NMAS listed. The overall trend is similar to that shown by Roberts et. al. (2009) in the literature review in that lower beta values are indicative of a mixture that is more resistant to rutting. While this trend does appear to be evident, comparison of two values may be called into question. The first value is the 9.5 NMAS PG 70-22 PM (65) mixture, which shows a lower beta value than the PG 76-22 mixture of the same NMAS. The second value is the beta for the 12.5 NMAS PG 70-22 PM mixture. In both instances the beta values indicate that the performance of the given mixture should be comparable, if not superior, to the higher binder grades of the similar NMAS.

Table 9-Master Curve Beta Estimation Parameter

\begin{tabular}{|c|c|c|}
\hline Binder Grade & NMAS & Beta Value \\
\hline PG 70-22 & 9.5 & -1.15 \\
\hline PG 70-22 PM (80) & 9.5 & -0.97 \\
\hline PG 70-22 PM (65) & 9.5 & -0.86 \\
\hline PG 76-22 & 9.5 & -0.91 \\
\hline PG 70-22 & 12.5 & -1.20 \\
\hline PG 70-22 PM & 12.5 & -1.01 \\
\hline PG 76-22 & 12.5 & -1.00 \\
\hline
\end{tabular}

\subsection{Flow Number Results}

Similar to dynamic modulus testing, testing for flow number went with only a few minor issues. The first issue arose with a specimen that was sliding out from in between the loading platens. When initially checked for end perpendicularity, the specimen appeared to be fine, however due to the issue testing of the specimen had to be stopped after 433 cycles before damage was potentially done to the machine. As the issue was clearly a problem with end perpendicularity, the specimen was again checked with it being determined that the sample was out of perpendicularity and the issue was not caught during the initial check. A new sample was not made, and the data collected from this sample was thrown out.

The second problem encountered involved a communication issue between the AMPT and the associated AMPT computer. Approximately half way through testing the issue was noted, however the issue did not proceed to interrupt the collection of data. It 
was not until specimen number 70 that the issue occurred during testing, resulting in the loss of data for that specimen. To solve the issue, Instrotek was consulted and provided a recommendation of turning off the power save mode for the USB ports. After this was done, the issue no longer occurred and no further data was lost.

A complete listing of the flow number results are presented in Appendix D

The final averaged flow number values and coefficient of variance for each binder grade and conditioning method are shown in Table 10 for the 9.5 NMAS mixtures, and Table 11 for the 12.5 NMAS mixture. Data presented in these tables uses a sample interval cycle of one and is presented in order to serve as a basis for comparison for several other methods that can be used to evaluate data received from flow number testing.

In addition to the sample interval cycle of one, the data presented in Table 12 and Table 13 present the averaged flow number and coefficient of variance (COV) using the highest sample interval cycle available of 20. Comparison of the two complete datasets was done using a one-way ANOVA, resulted in a p-value of 0.586 thus the null hypothesis of equal means could not be rejected indicating the samples are statistically similar. While the sample means prove to be statistically similar, the COV overall showed a downward trend. The average COV for both NMAS' went down, with the 9.5 NMAS COV decreasing by about $8 \%$ and the 12.5 NMAS decreasing by about $5 \%$. Regardless of the sample interval cycle, all data points were well within the single operator precision guidelines and are not suspect.

Table 10-9.5 NMAS Flow Number (n=1) Summary

\begin{tabular}{|c|c|c|c|c|c|c|c|c|}
\hline & \multicolumn{7}{|c|}{ Binder Grade } \\
\hline & \multicolumn{2}{|c|}{ PG 70-22 } & PG 70-22 M (80) & PG 70-22 M (65) & \multicolumn{2}{c|}{ PG 76-22 } \\
\hline & Average & $\begin{array}{c}\text { COV } \\
(\%)\end{array}$ & Average & $\begin{array}{c}\text { COV } \\
(\%)\end{array}$ & Average & $\begin{array}{c}\text { COV } \\
(\%)\end{array}$ & Average & $\begin{array}{c}\text { COV } \\
(\%)\end{array}$ \\
\hline $\begin{array}{c}\text { Dynamic } \\
\text { Modulus }\end{array}$ & 540.7 & 18.8 & 1025.0 & 3.5 & 1381.7 & 22.3 & 5291.7 & 65.7 \\
\hline $\begin{array}{c}\text { Flow Number } \\
\text { (2 Hr.) }\end{array}$ & 441.0 & 14.6 & 1164.3 & 24.8 & 1266.0 & 18.3 & 2616.5 & 25.2 \\
\hline $\begin{array}{c}\text { Flow Number } \\
\text { (4 Hr.) }\end{array}$ & 1031.3 & 14.9 & 3954.0 & 50.7 & 2794.0 & 13.0 & 4625.7 & 26.8 \\
\hline
\end{tabular}


Table 11-12.5 NMAS Flow Number (n=1) Summary

\begin{tabular}{|c|c|c|c|c|c|c|c|c|}
\hline & \multicolumn{9}{|c|}{ Binder Grade } \\
\hline & \multicolumn{2}{|c|}{ PG 70-22 } & PG 70-22 M (80) & PG 70-22 M (65) & \multicolumn{2}{|c|}{ PG 76-22 } \\
\hline & Average & $\begin{array}{c}\text { COV } \\
(\%)\end{array}$ & Average & $\begin{array}{c}\text { COV } \\
(\%)\end{array}$ & Average & $\begin{array}{c}\text { COV } \\
(\%)\end{array}$ & Average & $\begin{array}{c}\text { COV } \\
(\%)\end{array}$ \\
\hline $\begin{array}{c}\text { Dynamic } \\
\text { Modulus }\end{array}$ & 830.3 & 33.8 & 2409.7 & 27.4 & 1921.0 & 27.1 & 3157.3 & 13.8 \\
\hline $\begin{array}{c}\text { Flow Number } \\
\text { (2 Hr.) }\end{array}$ & 565.0 & 18.8 & 1499.3 & 22.6 & 1700.7 & 30.0 & 3673.7 & 32.5 \\
\hline $\begin{array}{c}\text { Flow Number } \\
\text { (4 Hr.) }\end{array}$ & 1849.7 & 41.9 & 6640.5 & 22.9 & 3754.7 & 26.1 & 7674.5 & 26.7 \\
\hline
\end{tabular}

Table 12-9.5 NMAS Flow Number $(n=20)$ Summary

\begin{tabular}{|c|c|c|c|c|c|c|c|c|}
\hline & \multicolumn{9}{|c|}{ Binder Grade } \\
\hline & \multicolumn{2}{|c|}{ PG 70-22 } & PG 70-22 M (80) & PG 70-22 M (65) & \multicolumn{2}{c|}{ PG 76-22 } \\
\hline & Average & $\begin{array}{c}\text { COV } \\
(\%)\end{array}$ & Average & $\begin{array}{c}\text { COV } \\
(\%)\end{array}$ & Average & $\begin{array}{c}\text { COV } \\
(\%)\end{array}$ & Average & $\begin{array}{c}\text { COV } \\
(\%)\end{array}$ \\
\hline $\begin{array}{c}\text { Dynamic } \\
\text { Modulus }\end{array}$ & 530.7 & 0.4 & 1141.7 & 6.2 & 1250.3 & 27.8 & 4005.7 & 43.3 \\
\hline $\begin{array}{c}\text { Flow Number } \\
\text { (2 Hr.) }\end{array}$ & 480.0 & 13.2 & 1101.7 & 11.6 & 1381.3 & 11.9 & 2490 & 0.9 \\
\hline $\begin{array}{c}\text { Flow Number } \\
\text { (4 Hr.) }\end{array}$ & 1080.0 & 3.9 & 4283.7 & 44.8 & 3407.7 & 20.1 & 4723.7 & 21.3 \\
\hline
\end{tabular}

Table 13-12.5 NMAS Flow Number $(n=20)$ Summary

\begin{tabular}{|c|c|c|c|c|c|c|c|c|}
\hline & \multicolumn{9}{|c|}{ Binder Grade } \\
\hline & \multicolumn{2}{|c|}{ PG 70-22 } & PG 70-22 M (80) & PG 70-22 M (65) & \multicolumn{2}{c|}{ PG 76-22 } \\
\hline & Average & $\begin{array}{c}\text { COV } \\
(\%)\end{array}$ & Average & $\begin{array}{c}\text { COV } \\
(\%)\end{array}$ & Average & $\begin{array}{c}\text { COV } \\
(\%)\end{array}$ & Average & $\begin{array}{c}\text { COV } \\
(\%)\end{array}$ \\
\hline $\begin{array}{c}\text { Dynamic } \\
\text { Modulus }\end{array}$ & 816.0 & 19.3 & 2368.0 & 28.9 & 1936.0 & 9.6 & 4045.3 & 32.2 \\
\hline $\begin{array}{c}\text { Flow Number } \\
\text { (2 Hr.) }\end{array}$ & 609.0 & 11.4 & 1482.0 & 23.3 & 1955.3 & 22.4 & 7025.7 & 31.4 \\
\hline $\begin{array}{c}\text { Flow Number } \\
\text { (4 Hr.) }\end{array}$ & 1907.7 & 56.2 & 5445.5 & 12.8 & 4373.7 & 9.8 & 8033 & 9.7 \\
\hline
\end{tabular}

In addition to the flow number data, the flow number index was computed using the accumulated strain at the indicated flow number. The results from this calculation are shown in Table 14 for the 9.5 NMAS and Table 15 for the 12.5 NMAS and used a sample interval cycle of one. Overall the effects of finding the flow number index were similar to 
those of increasing the sample interval cycle. Again, the average value for both COV's went down, with the 9.5 NMAS decreasing by about 4\% and the 12.5 NMAS decreasing by about $5 \%$.

Table 14-9.5 NMAS Flow Number Index

\begin{tabular}{|c|c|c|c|c|c|c|c|c|}
\hline & \multicolumn{9}{|c|}{ Binder Grade } \\
\hline & \multicolumn{2}{|c|}{ PG 70-22 } & \multicolumn{2}{|c|}{ PG 70-22 M (80) } & PG 70-22 M (65) & \multicolumn{2}{c|}{ PG 76-22 } \\
\hline & Average & $\begin{array}{c}\text { COV } \\
(\%)\end{array}$ & Average & $\begin{array}{c}\text { COV } \\
(\%)\end{array}$ & Average & $\begin{array}{c}\text { COV } \\
(\%)\end{array}$ & Average & $\begin{array}{c}\text { COV } \\
(\%)\end{array}$ \\
\hline $\begin{array}{c}\text { Dynamic } \\
\text { Modulus }\end{array}$ & 37.0 & 7.8 & 22.2 & 5.0 & 17.6 & 26.7 & 6.1 & 49.2 \\
\hline $\begin{array}{c}\text { Flow Number } \\
\text { (2 Hr.) }\end{array}$ & 45.3 & 15.2 & 22.0 & 22.3 & 18.9 & 14.3 & 9.8 & 6.1 \\
\hline $\begin{array}{c}\text { Flow Number } \\
\text { (4 Hr.) }\end{array}$ & 19.4 & 12.4 & 8.1 & 55.6 & 8.3 & 15.7 & 6.2 & 19.4 \\
\hline
\end{tabular}

Table 15-12.5 NMAS Flow Number Index

\begin{tabular}{|c|c|c|c|c|c|c|c|c|}
\hline & \multicolumn{9}{|c|}{ Binder Grade } \\
\hline & \multicolumn{2}{|c|}{ PG 70-22 } & \multicolumn{2}{|c|}{ PG 70-22 M (80) } & PG 70-22 M (65) & \multicolumn{2}{c|}{ PG 76-22 } \\
\hline & Average & $\begin{array}{c}\text { COV } \\
(\%)\end{array}$ & Average & $\begin{array}{c}\text { COV } \\
(\%)\end{array}$ & Average & $\begin{array}{c}\text { COV } \\
(\%)\end{array}$ & Average & $\begin{array}{c}\text { COV } \\
(\%)\end{array}$ \\
\hline $\begin{array}{c}\text { Dynamic } \\
\text { Modulus }\end{array}$ & 27.6 & 24.6 & 10.5 & 31.4 & 12.2 & 18.9 & 7 & 15.7 \\
\hline $\begin{array}{c}\text { Flow Number } \\
\text { (2 Hr.) }\end{array}$ & 39.3 & 25.2 & 19.1 & 39.3 & 13.7 & 29.2 & 5.5 & 7.3 \\
\hline $\begin{array}{c}\text { Flow Number } \\
\text { (4 Hr.) }\end{array}$ & 13.6 & 36.8 & 4.1 & 17.1 & 6.2 & 9.7 & 3.4 & 5.9 \\
\hline
\end{tabular}

\subsection{Statistical Analysis}

Statistical analysis of the flow number data looked primarily at two key areas, binder grade and test sequence (whether or not the sample was tested for dynamic modulus before testing for flow number). No statistical analysis of dynamic modulus values was performed because analysis of the results was performed on averaged values. An initial ANOVA was performed comparing the 9.5 NMAS mixtures and 12.5 NMAS mixtures. The results from this analysis are shown in Table 16. With a p-level of 0.245, there is insufficient evidence to reject the null hypothesis of equal means. The results of the remaining ANOVA's are shown in Table 17 for the 9.5 NMAS mixtures and Table 18 
for the 12.5 NMAS mixtures. The analysis for both mixes rejects the null hypothesis of equal means. The ANOVA determined that there was an interaction effect between the binder grades and testing sequence, for the 9.5 NMAS mixture; the interaction effect was rejected for the 12.5 NMAS mixes.

Table 16-9.5 NMAS vs. 12.5 NMAS ANOVA Results

\begin{tabular}{|c|c|c|c|c|c|c|}
\hline Source of Variation & SS & d.f. & MS & F & p-level & F crit \\
\hline Between Groups & 5442669.57 & 1 & 5442670 & 1.37423 & 0.24524 & 3.98405 \\
\hline Within Groups & 265354929 & 67 & 3960521 & & & \\
\hline Total & 270797599 & 68 & & & & \\
\hline
\end{tabular}

Table 17-9.5 NMAS ANOVA Results

\begin{tabular}{|l|c|c|c|c|c|c|}
\hline \multicolumn{1}{|c|}{ Source of Variation } & SS & d.f. & MS & F & $\begin{array}{c}\text { p- } \\
\text { level }\end{array}$ & F crit \\
\hline Factor \#1 (Test Sequence) & $19,684,519$ & 2 & $9,842,260$ & 6.196 & 0.007 & 3.422 \\
\hline Factor \#2 (Binder Grade) & $60,328,032$ & 3 & $20,109,344$ & 12.66 & 0.000 & 3.028 \\
\hline $\begin{array}{l}\text { Factor \#1 \#2 (Test Sequence } \\
\text { Binder Grade) }\end{array}$ & $10,532,155$ & 6 & $1,755,359$ & 1.105 & 0.39 & 2.528 \\
\hline Within Groups & $36,533,129$ & 23 & $1,588,397$ & & & \\
\hline Total & $127,077,836$ & 34 & $3,737,583$ & & & \\
\hline
\end{tabular}

Table 18-12.5 NMAS ANOVA Results

\begin{tabular}{|l|c|c|c|c|c|c|}
\hline \multicolumn{1}{|c|}{ Source of Variation } & SS & d.f. & MS & F & $\begin{array}{c}\text { p- } \\
\text { level }\end{array}$ & F crit \\
\hline Factor \#1 (Test Sequence) & $47,082,778$ & 2 & $23,541,389$ & 34.024 & 0.000 & 3.443 \\
\hline Factor \#2 (Binder Code) & $50,876,276$ & 3 & $16,958,759$ & 24.511 & 0.000 & 3.049 \\
\hline $\begin{array}{l}\text { Factor \#1 \#2 (Test Sequence x } \\
\text { Binder Code) }\end{array}$ & $25,096,305$ & 6 & $4,182,717$ & 6.045 & 0.001 & 2.549 \\
\hline Within Groups & $15,221,734$ & 22 & 691,897 & & & \\
\hline Total & $138,277,094$ & 33 & $4,190,215$ & & & \\
\hline
\end{tabular}

Comparison of testing sequence found the sample means for flow number testing performed after testing for dynamic modulus is statistically the same as testing a specimen for only flow number with only a two hour oven aging time. This result holds true for both the 9.5 NMAS and 12.5 NMAS with p-values of 0.137 and 0.522 respectively. 
Further analysis evaluating the effects of oven age time, testing for only flow number with 2 and 4 hour oven aging times, resulted in the rejection of statistically similar means. It was found, with p-values of 0.001 for the 9.5 NMAS mixtures and approximately 0 for the 12.5 NMAS mixtures, that at a 0.05 significance level the sample means were not equal. Aging the samples for 4 hours significantly increased the flow number, consistently across all of sample groups tested.

Table 19-9.5 NMAS Fisher LSD Test Comparison

\begin{tabular}{|l|r|r|r|}
\hline \multicolumn{1}{|c|}{$\begin{array}{c}\text { Group vs. Group } \\
\text { (Contrast) }\end{array}$} & \multicolumn{1}{c|}{$\begin{array}{c}\text { Test } \\
\text { Difference }\end{array}$} & Statistics & p-level \\
\hline FN w/ DM vs. w/o & 800.93 & 1.522 & 0.137 \\
\hline FN w/ DM vs. FN (4 Hr.) & $-1,041.50$ & 2.024 & 0.051 \\
\hline FN (2 Hr.) vs. FN (4 Hr.) & $-1,842.43$ & 3.502 & 0.001 \\
\hline
\end{tabular}

Table 20-12.5 NMAS Fisher LSD Test Comparison

\begin{tabular}{|l|c|c|c|}
\hline \multicolumn{1}{|c|}{$\begin{array}{c}\text { Group vs. Group } \\
\text { (Contrast) }\end{array}$} & Difference & $\begin{array}{c}\text { Test } \\
\text { Statistics }\end{array}$ & $\begin{array}{c}\text { p- } \\
\text { level }\end{array}$ \\
\hline FN w/ DM vs. w/o & 219.92 & 0.648 & 0.522 \\
\hline FN w/ DM vs. FN (4 Hr.) & $-2,464.72$ & 6.920 & 0.000 \\
\hline FN (2 Hr.) vs. FN (4 Hr.) & $-2,684.63$ & 7.538 & 0.000 \\
\hline
\end{tabular}

Similar to the comparison for testing sequence, the comparison of the various binder grades was performed with Table 21 showing the results from this testing for the 9.5 NMAS mixture. For the 9.5 NMAS, the PG 70-22 was found to be statistically similar to the PG 70-22 PM compacted to 65 gyrations with a p-value of 0.063 . However, comparison of the PG 70-22 to PG 70-22 PM compacted to 80 gyrations found that the sample means were not statistically similar, with a p-value of 0.027. The PG 70-22 PM performed better than the PG 70-22, with overall higher flow numbers.

Additional comparison was done on the performance of the PG 70-22 PM compacted to the two different gyration levels. This analysis resulted in the determination that both gyration levels were statistically the same, with a p-value of 0.696 . Finally, comparison of the flow numbers between both PG 70-22 PM mixtures to the PG 76-22 resulted in the determination that the sample means were not statistically similar, with p- 
values of 0.001 for the 80 gyration mixture and approximately 0 for the 65 gyration mixture.

Table 21-9.5 NMAS Fisher LSD Binder Comparison

\begin{tabular}{|l|c|c|c|}
\hline \multicolumn{1}{|c|}{ Group vs. Group (Contrast) } & Difference & $\begin{array}{c}\text { Test } \\
\text { Statistics }\end{array}$ & p-level \\
\hline PG 70-22 vs. PG 70-22 (80) & $-1,376.78$ & 2.317 & 0.027 \\
\hline PG 70-22 vs. PG 70-22 (65) & $-1,142.89$ & 1.924 & 0.063 \\
\hline PG 70-22 vs. PG 76-22 & $-3,702.13$ & 6.045 & 0.000 \\
\hline PG 70-22 (80) vs. PG 70-22 (65) & 233.89 & 0.394 & 0.696 \\
\hline PG 70-22 (80) vs. PG 76-22 & $-2,325.35$ & 3.797 & 0.001 \\
\hline PG 70-22 (65) vs. PG 76-22 & $-2,559.24$ & 4.179 & 0.000 \\
\hline
\end{tabular}

Results from the 12.5 NMAS flow number data resulted in similar comparison results to the 9.5 NMAS mixtures, with the results being shown in Table 22. One difference however is the rejection that both sample means from the PG 70-22 PM specimens compacted to the different gyration levels were the same. With p-values of approximately 0 for the 80 -gyration level and 0.001 for the 65 -gyration level, the null hypothesis of equal means was rejected.

Comparison of the PG 70-22 PM mixtures designed to different compaction levels did not reject the null hypothesis of equal means, suggesting sample means are similar, with a p-value of 0.109. Again, comparison of both PG 70-22 PM gyrations levels to the PG 76-22 resulted in the rejection of the null hypothesis with a p-value of 0.003 for the 80 -gyration mixture and approximately 0 for the 65 gyration mixture.

Table 22-12.5 NMAS Fisher LSD Binder Comparison

\begin{tabular}{|l|r|r|r|}
\hline \multicolumn{1}{|c|}{ Group vs. Group (Contrast) } & \multicolumn{1}{c|}{ Difference } & \multicolumn{1}{c|}{ Statistics } & p-level \\
\hline PG 70-22 vs. PG 70-22(80) & $-2,044.33$ & 5.058 & 0.000 \\
\hline PG 70-22 vs. PG 70-22 (65) & $-1,377.11$ & 3.512 & 0.001 \\
\hline PG 70-22 vs. PG 76-22 & $-3,398.58$ & 8.409 & 0.000 \\
\hline PG 70-22 (80) vs. PG 70-22 (65) & 667.22 & 1.651 & 0.109 \\
\hline PG 70-22 (80) vs. PG 76-22 & $-1,354.25$ & 3.256 & 0.003 \\
\hline PG 70-22 (65) vs. PG 76-22 & $-2,021.47$ & 5.001 & 0.000 \\
\hline
\end{tabular}




\section{Conclusions and Recommendations}

\subsection{Conclusions}

This research had multiple objectives, most of which involved establishing the implementation of the Asphalt Mixture Performance Tester for use in the Asphalt Technology Laboratory. In addition to implementing the AMPT, research was performed evaluating a new binder grade developed by Marathon Petroleum. This additional research aided in verifying that the data initially collected by the AMPT reasonable with respect to that found in the literature review.

As exampled in the methodology and the procedure outlined in Appendix A, a clear approach has be developed for creating specimens to be tested in the AMPT and for testing specimens for dynamic modulus and flow number. The initial setup of both the AMPT and the specimen preparation equipment, along with problems encountered during setup are documented in Appendix B. In addition, several problems encountered during the course of testing are outlined in the results section. Along with these problems, the solutions to the problems are also given.

The data collected from this study also results in the following conclusions:

- Trends in the initial data collected using the AMPT are consistent with those shown in the literature review.

- Oven age time does have a significant effect on flow number results.

- Dynamic modulus testing prior to testing for flow number does not have a statistically significant effect on the results of flow number testing.

- The polymer modified PG 70-22 overall performed better than the unmodified version with regard to flow number rutting resistance.

- Dynamic modulus testing did not show the same improved performance in the unmodified PG 70-22 binder when compared to the modified version.

- The PG 76-22 PM performed better than both the unmodified and polymer modified versions of PG 70-22. 


\subsection{Recommendations}

The data in this study is only a small fraction of potential data that can come from the implementation of the AMPT. This research only looked at three binder grades and two NMAS gradations, with aggregate locally sourced. Further research should be done to expand the data collected, with the idea of compiling a database that contains relevant information to various mix designs. One key piece of information that should be collected are the air voids of the gyratory compacted specimens and finish sawed and cored AMPT specimens as further research and evaluation would likely aid in the preparation of the gyratory specimens that are suitable for testing with minimal trial and error.

In addition, research into the various methods for predicting flow number and evaluating the rutting potential of a mixture based on the flow number is necessary. It is also recommended that the use of the beta parameter found in the generation of dynamic modulus master curves be looked into for evaluating the variations in binder grades.

While the overall rutting performance of the polymer modified PG 70-22 exceeded that of the unmodified version, further comparisons should be done to evaluate the fatigue resistance. 


\section{References}

Advanced Asphalt Technologies. NCHRP Report 673 A Manual for Design of Hot Mix Asphalt with Commentary. Washington, D.C.: Transportation Research Board, 2011.

Apeagyei, A.K. and B.K. Diefenderfer. "Asphalt concrete rutting resistance assessment by the flow number test." Proc. Of Transportation and Development Institute, Chicago. 406-17.

Bonaquist, R. F. Ruggedness Testing of the Dynamic Modulus and Flow Number Tests with the Simple Performance Tester. Washington, D.C.: Transportation Research Board, 2008.

Bonaquist, R. NCHRP09-29_mastersolver2-2. Microsoft Excel file. Web. Washington, D.C.: Transportation Research Board, 3 Apr. 2009. XLS. http://onlinepubs.trb.org/onlinepubs/nchrp/docs/NCHRP09-29_mastersolver22.xls

Bonaquist, R. F. NCHRP Report 702 Precision of the Dynamic Modulus and Flow Number Tests Conducted with the Asphalt Mixture Performance Tester. Washington, D.C.: Transportation Research Board, 2011.

Clyne T. R., X. Li, M. O. Marasteanu, E. L. Skok, DYNAMIC AND RESILIENT MODULUS OF MN/DOT ASPHALT MIXTURES, MN/RC - 2003-09 Department of Civil Engineering University of Minnesota 500 Pillsbury Dr. S.E. Minneapolis, MN 55455-0116, 2003.

Diaz, L. G., and A. R. Archilla. "From Testing to Design: An Easy Way to Use and Interpret the Results from the Asphalt Mixture Performance Tester (AMPT)." International Journal of Pavement Research and Technology 6.5 (2013): 527-38. Chinese Society of Pavement Engineering.

"Demystifying the Dynamic Modulus Master Curve." Asphalt Technology E-News 26 (2014). National Center for Asphalt Technology. 
Dongré, R., J. D'angelo, and A. Copeland. "Refinement of Flow Number as Determined by Asphalt Mixture Performance Tester." Transportation Research Record: Journal of the Transportation Research Board 2127.-1 (2009): 127-36.

Freund, R. J., W. J. Wilson, and D. L. Mohr. Statistical Methods. Amsterdam: Elsevier, 2010.

Li, P., Z. Ding, and Z. Zhang. "Effect of Temperature and Frequency on Visco-Elastic Dynamic Response of Asphalt Mixture." Journal of Testing and Evaluation 41.4 (2013): 20120044.

Li, Q., F. Ni, L.Gao, Q. Yuan, and Y. Xiao. "Evaluating the Rutting Resistance of Asphalt Mixtures Using an Advanced Repeated Load Permanent Deformation Test under Field Conditions." Construction and Building Materials 61 (2014): 241-51.

LTPPBind Download. Computer software. LTPP: Long-Term Pavement Performance Program--. Vers. 3.1. Federal Highway Administration Research and Technology. Web.

Mogawer, W. S., A. J. Austerman, J. S. Daniel, F. Zhou, and T.Bennert. "Evaluation of the Effects of Hot Mix Asphalt Density on Mixture Fatigue Performance, Rutting Performance and MEPDG Distress Predictions." International Journal of Pavement Engineering 12.2 (2011): 161-75.

Pellinen, T., and M.Witczak. "Use of Stiffness of Hot-Mix Asphalt as a Simple Performance Test." Transportation Research Record 1789.1 (2002): 80-90.

Roberts, L., P. Romero, K. Vanfrank, and R.Ferrin. "Evaluation of Asphalt Mixture Performance Tester." Transportation Research Record: Journal of the Transportation Research Board 2296.-1 (2012): 69-76.

Rowe, G. M., S. H. Khoee, P. Blankenship, and K. C. Mahboub. "Evaluation of Aspects of $E^{*}$ Test by Using Hot-Mix Asphalt Specimens with Varying Void Contents." Transportation Research Record: Journal of the Transportation Research Board 2127.-1 (2009): 164-72. 
"Standard Method of Test for Determining the Dynamic Modulus and Flow Number for Asphalt Mixtures Using the Asphalt Mixture Performance Tester (AMPT) TP 7913." Standard Specifications for Transportation Materials and Methods of Sampling and Testing (33rd Edition) and AASHTO Provisional Standards, 2013 Edition. Knovel.

"Standard Practice for Developing Dynamic Modulus Master Curves for Asphalt Mixtures Using the Asphalt Mixture Performance Tester (AMPT) PP 61-13." Standard Specifications for Transportation Materials and Methods of Sampling and Testing (33rd Edition) and AASHTO Provisional Standards, 2013 Edition. Knovel.

"Standard Practice for Preparation of Cylindrical Performance Test Specimens Using the Superpave Gyratory Compactor (SGC) PP 60-13." Standard Specifications for Transportation Materials and Methods of Sampling and Testing (33rd Edition) and AASHTO Provisional Standards, 2013 Edition. Knovel.

StatPlus for Mac. Computer software. Vers. 5. AnalystSoft Inc.

Instrotek. "Universal Testing Software UTS Test No 005 AMPT Flow.” Victoria, Australia: IPC Global, 2010. Print.

Williams, M. L., Landel, R. F., and Ferry, J. D., "The Temperature Dependence of Relaxation Mechanism in Amorphous Polymers and Other Glass-Liquids,” J. of Am. Chem. Soc., Vol. 77, 1955, p. 370.

Witczak, M. W. Simple Performance Tests: Summary of Recommended Methods and Database. Washington, D.C.: Transportation Research Board, 2005.

Zhang, J., A.E. Alvarez, S. I. Lee, A. Torres, and L. F. Walubita. "Comparison of Flow Number, Dynamic Modulus, and Repeated Load Tests for Evaluation of HMA Permanent Deformation." Construction and Building Materials 44 (2013): 39198. 


\section{Appendix A - AMPT User Guide}

This research was the first use of the AMPT in the WVU Asphalt Technology Laboratory. Although standard methods were followed to the extent possible, this appendix documents the specific procedures followed during this research.

\section{Sample Preparation}

1. Using the Superpave Gyratory Compactor compact samples to 170 to $180 \mathrm{~mm}$ in height with $180 \mathrm{~mm}$ recommended here through experience. Samples should aim to have $7 \pm 0.5 \%$ VTM. Bulk specific gravities should be performed on compacted samples to determine if they are relatively close to this range.

2. After cooling overnight and finding the bulk specific gravities, the samples should be cut to a length of $150 \pm 2.5 \mathrm{~mm}$ in length. Slowly cut.

3. After cutting the sample should be cored. Again slowly.

4. Following coring and cutting of the specimen, the sample should be dried using the CoreDry and tested for VTM using the CoreLok. If the test specimen is within the $7 \pm 0.5 \%$ VTM range, it can continue to be used, if it is not within this range, the sample is void and must be remade.

5. Next check the sample for perpendicularity. A $0.5 \mathrm{~mm}$ wire must not be able to be slid under the blade when the beam is placed along the length of the specimen, when checked at 3 spots A $1.0 \mathrm{~mm}$ wire must not be able to be slid under the blade when the beam is placed across the diameter of the specimen, when checked at 2 spots. If the test specimen meets these requirements, it can continue to be used. If not, the sample must be remade.

6. Three diameter measurements at the center and $1 / 3$ points should be taken. The average diameter shall be between 98 and $104 \mathrm{~mm}$ with a standard deviation of no more than $0.5 \mathrm{~mm}$.

7. Four height measurements at approximately $1 / 4$ points should be taken. The average height shall be between 147.5 and $152.5 \mathrm{~mm}$ with a standard deviation of no more than $0.5 \mathrm{~mm}$.

8. AASHTO TP79-13 recommends storage of the specimen on its end on a flat shelf with in a temperature controlled room between 15 and $27^{\circ} \mathrm{C}$. 


\section{Specimen Testing}

1. Samples should be conditioned overnight at the required testing temperature that is being performed.

2. Turn on the AMTP and allow the environmental chamber to equilibrate to test temperature for at least 1 hour prior to testing. The top and bottom platens, with the ball bearing if needed, should be placed in the chamber to minimize the time needed to reach an equilibrium temperature for the first specimen being tested.

3. Click on the virtual pendant button to check the hydraulic system, and to warm the system up.

3.1. Once the Virtual Pendant is open, select low in the hydraulic power supply bar.

3.2. Wait a few seconds and then select high in the hydraulic power supply bar.

3.3. Now select low under the hydraulic service manifold bar.

3.4. Wait until the pitch of the sound coming from the machine changes into a higher pitch. This typically takes about 5 seconds.

3.5. Once the sound changes, select high under the hydraulic service manifold bar.

- Note: Should the actuator move up during the course of this, simply press and hold the axis jog control down button down.

3.6. After allowing the system to run for a few minutes, start with step 3.5 and proceed toward step 3.1 to shut off the hydraulic system.

4. Ensure the dummy specimen, being conditioned in the same manner as the samples being tested, is at the required testing temperature before continuing.

5. Turn on the AMPT associated computer and open the UTS Launcher.

6. There are 2 different tests these instructions will cover:

\subsection{Dynamic Modulus Testing}

6.1.1. Select UTS006 Dynamic Modulus from the Recent Tests or Installed Tests Menu

-Note: Previous test data will likely show up. This can be ignored, as it is already saved and will go away in the next step.

6.1.2. Select the File dropdown menu, Template menu, and click on open template. 
6.1.2.1. Five templates should show up. If not ensure you are under the following drive location: -IPCglobal $>006$ Dynamic Moduls $>$ Templates

6.1.2.2. Select the appropriate testing temperature, as necessary for the high testing temperature the proper high PG binder grade and open the template.

-Note: Selection of the proper test is critical. These templates have all the required frequencies and temperatures, in accordance with PP 61-13, input into the program.

6.1.3. Select the New button to create a new test file for the sample being tested. -Note: Under the Options dropdown menu, there should be a check mark next to Strict template rules. This will prevent the template file from being over written by failing to adhere to this step.

-Steps 6.1.4 through 6.1.6 may be performed immediately following 6.1.3 or while the environmental chamber is reaching an equilibrium temperature after placing the specimen in for testing based on personal preference.

\subsubsection{Select the General tab.}

6.1.4.1. Input the appropriate Project Name.

6.1.4.2. Input the appropriate Operator Name.

6.1.4.3. Check the comments to ensure the appropriate information is input. You may also input any comments you desire to make.

6.1.5. Select the Setup and Control tab.

\subsubsection{Under Specimen Identification:}

6.1.5.1.1. Input the appropriate Identification.

6.1.5.1.2. Input the appropriate Conditioning time. This is the time spent at the testing temperature.

6.1.5.1.3. Input any specimen properties or comments.

6.1.5.2. Input the appropriate specimen dimensions.

- Note: If the Help Prompt is active, the specimen diameter and height boxes will only be checked more than 2 inputs are made. 
6.1.6. Check that the appropriate frequencies, testing temperature, confining stress, Initial modulus, axial gauge length, and average strain ranges are input or selected.

-Note: The Modulus is only a rough guess as to where the machine should be begin testing. It does not need to be incredibly accurate as the machine self adjusts.

-Note: The steps6.1.7 through 6.1 .18 must be performed within 5 minutes and should be read prior to starting them.

6.1.7. Remove specimen from the conditioning chamber.

6.1.8. Place the clips that will hold the LVDT's in place on the points placed on the specimen. The black side of the clips should be facing away from each other, with the silver sides facing toward each other.

6.1.9. Raise the containment cell on the environmental chamber through the UTS software.

6.1.10. The sample may now be placed between the top and bottom platens, with a TFE-Fluorocarbon sheet between the specimen and both platens. A greased double latex friction reducer may also be used.

6.1.11. Place the assembled specimen on the loading actuator in the environmental chamber.

6.1.12. Plug the LVDT's into the appropriate, color coded connection. Ensure the red dot on the LVDT wire is lined up with the red line on the plug connection.

-Note 1: DO NOT force the plug into the connection

-Note 2: It is important to ensure the proper LVDT is plugged into the correct connector. Each LVDT sends a signal to a card that is calibrated specifically for that LVDT. If the wrong LVDT is plugged into the wrong spot, the readings will be wrong and your data will be wrong.

6.1.13. Click on the Levels button and to open the Transducer Levels window.

6.1.14. Place the LVDT's between the clips mounted on the specimen.

6.1.14.1. During the placement ensure that each LVDT is not too far from the center of its reading capabilities. If the reading is too far to the 
sensors maximum or minimum readings capabilities, the changes in length may not be fully recognized leading to an error in your data.

6.1.14.2. If needed adjust the length of the LVDT by loosening the brass end piece and then screwing the sensor end in or out. When finished, be sure to tighten the brass end piece to fix the sensors length.

-Note: Once adjusted to the proper length for the test specimens, no further adjustments are typically needed. Adjustments between the verification sample and the actual test samples may be necessary however.

6.1.15. Once finished making any necessary adjustments, make one final check to ensure everything is properly set up and connected.

6.1.16. Click on the Lower button to lower the cell, but do not press the ok button on the prompt that appears.

6.1.17. Using the two buttons on the front of the machine begin to lower the confinement cell. These buttons are a dead man switch, i.e. when only on is depressed nothing happens however when both are depressed, the cell is lowered.

6.1.18. Approximately half way down, stop to check all wires are within the confinement cell and the LVDT's are all still in place. Also ensure there are no obstructions below the confinement cell. If everything is ok, continue to lower the cell.

6.1.19. Before completely lowering the cell again check that no objects are in the path of the cell and the sample is still ok.

6.1.20. Once the cell has been completely lowered, click OK on the prompt still displayed on the computer to acknowledge that the cell has been completely lowered.

6.1.21. Allow the environmental chamber to reach an equilibrium temperature.

The time required for this varies based on the testing temperature.

6.1.22. Once an equilibrium temperature has been reached, click on the virtual pendant button to start the hydraulic systems. 
6.1.22.1. Once the Virtual Pendant is open, select low in the hydraulic power supply bar.

6.1.22.2. Wait a few seconds and then select high in the hydraulic power supply bar.

6.1.22.3. Now select low under the hydraulic service manifold bar.

6.1.22.4. Wait until the pitch of the sound coming from the machine changes into a higher pitch. This typically takes about 5 seconds. Once the sound changes, select high under the hydraulic service manifold bar.

6.1.23. Click the start button to begin the test. If Ask for data file name is checked under the Options dropdown menu, the program will ask you to save the file upon selecting the start button. The generic save name is the input sample id.

6.1.24. After saving the file, a command prompt will appear and the Test Data tab will be selected. This command prompt informs you that the initial contact stress and confinement pressure are being applied. Once the appropriate levels have been reached, as displayed in the upper left, select start and the test will begin. If a problem occurs press abort and restart after correcting the problem.

6.1.25. Once testing has begun, all data is saved in real time. Should the program crash, power go out, or some other unforeseen event interrupt the test, all data up to that point will be available in the data file.

6.1.26. Testing for dynamic modulus is performed in two steps with this software. Step 1 is a Preconditioning phase to help the computer to adjust the initial dynamic modulus. Step 2 clears the data from Step 1 but starts with the adjusted modulus found from Step 1. Each Step performs 10 loading cycles over various times, determined from the frequencies selected.

6.1.27. Upon completion of the test, the actuator will automatically lower and Completed will appear in the machine status bar.

6.1.28. Power down the hydraulic system by reversing steps 3.1 through 3.5 .

6.1.29. The program can now be either closed, or a new file created to continue testing. When prompted about saving changes made to the template file select no. The data from the test has already been saved and you do not want to change anything about the template files. 


\subsection{Flow Number Testing}

6.2.1. Select UTS005 SPT Flow Test from the Recent Tests or Installed Tests Menu

-Note: Previous test data will likely show up. This can be ignored, as it is already saved and will go away in the next step.

6.2.2. Select the File dropdown menu, Template menu, and click on open template.

6.2.2.1. One template titled "Default Template" should show up. If not ensure you are under the following drive location:

\section{-IPCglobal $>005$ SPT Flow Test $>$ Templates}

-Note: To simplify the process when testing a large number of samples, it is easier to input the data outline in steps 6.2 .3 and the desired testing temperature, contact stress and deviator stress, and then go to File $>$ Template $>$ Save template as. This will save the basic testing data and only the specimen specific data will need to be entered.

\subsubsection{Select the General tab.}

6.2.3.1. Input the appropriate Project Name.

6.2.3.2. Input the appropriate Operator Name.

6.2.3.3. Check the comments to ensure the appropriate information is input. You may also input any comments you desire to make.

\subsubsection{Select the Setup and Control tab.}

\subsubsection{Under Specimen Identification:}

6.2.4.1.1. Input the appropriate Identification.

6.2.4.1.2. Input the appropriate Conditioning time. This is the time spent at the testing temperature.

6.2.4.1.3. Input any specimen properties or comments.

6.2.4.2. Input the appropriate specimen dimensions.

- Note: If the Help Prompt is active, the specimen diameter and height boxes will only be checked more than 2 inputs are made. 
6.2.5. Fabrication of the greased double latex friction reducer can be performed at any time prior to the opening of the containment cell. The next steps outline the procedure from AASHTO TP 79-13 for fabrication of the friction reducers.

6.2.5.1. Take one piece of circular latex and place it on a scale capable of reading to the 0.01 .

6.2.5.2. Zero the scale and place $0.25 \pm 0.5 \mathrm{~g}$ of silicon grease in the center of the latex.

6.2.5.3. Spread the grease in a circular manner from the inside, working the grease towards the outside.

6.2.5.4. Once evenly spread, take a second piece of circular latex and place it on top.

6.2.5.5. Repeat the process to obtain two double greased latex end friction reducers, one for the top and one for the bottom.

Note: Steps 6.2.6 through.....

6.2.6. Remove specimen from the conditioning chamber.

6.2.7. Raise the containment cell on the environmental chamber through the UTS software.

6.2.8. Place the double greased latex end friction reducers on the top and bottom between the specimen ends and the top and bottom platens.

6.2.9. Place the assembled specimen on the loading actuator in the environmental chamber.

6.2.10. Place the assembled specimen on the loading actuator in the environmental chamber.

6.2.11. Click on the Lower button to lower the cell, but do not press the ok button on the prompt that appears.

6.2.12. Using the two buttons on the front of the machine begin to lower the confinement cell. These buttons are a dead man switch, i.e. when only on is depressed nothing happens however when both are depressed, the cell is lowered.

6.2.13. Approximately half way down, stop to ensure there are no obstructions below the confinement cell. If everything is ok, continue to lower the cell. 
6.2.14. Before completely lowering the cell again check that no objects are in the path of the cell and the sample is still ok.

6.2.15. Once the cell has been completely lowered, click OK on the prompt still displayed on the computer to acknowledge that the cell has been completely lowered.

6.2.16. Allow the environmental chamber to reach an equilibrium temperature. The time required for this varies based on the testing temperature.

6.2.17. Once an equilibrium temperature has been reached, click on the virtual pendant button to start the hydraulic systems.

6.2.17.1. Once the Virtual Pendant is open, select low in the hydraulic power supply bar.

6.2.17.2. Wait a few seconds and then select high in the hydraulic power supply bar.

6.2.17.3. Now select low under the hydraulic service manifold bar.

6.2.17.4. Wait until the pitch of the sound coming from the machine changes into a higher pitch. This typically takes about 5 seconds. Once the sound changes, select high under the hydraulic service manifold bar.

6.2.18. Click the start button to begin the test. If Ask for data file name is checked under the Options dropdown menu, the program will ask you to save the file upon selecting the start button. The generic save name is the input sample id.

6.2.19. After saving the file, a command prompt will appear and the Test Data tab will be selected. This command prompt informs you that the initial contact stress and confinement pressure are being applied. Once the appropriate levels have been reached, as displayed in the upper left, select start and the test will begin. If a problem occurs press abort and restart after correcting the problem.

6.2.20. Once testing has begun, all data is saved in real time. Should the program crash, power go out, or some other unforeseen event interrupt the test, all data up to that point will be available in the data file.

6.2.21. Testing for flow number applies a deviator stress pulse for 0.1 seconds, followed by a 0.9 second resting time, for a total of 1 second per testing cycle. 
6.2.22. The flow number test will conclude once the preset total cycles or accumulated strain value is met. Unlike testing for dynamic modulus, the machine will automatically lower the specimen and shut the machine down. No further user input is required except to raise the cell and remove the test specimen. 
Sample ID

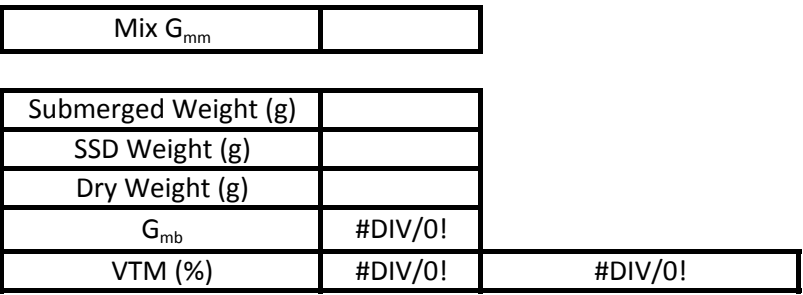

\begin{tabular}{|c|c|c|}
\hline Diameter & $\mathrm{mm}$ to the nearest 0.1 & \\
\hline 1/3 Point & 100.00 & \\
\hline Center Point & 100.00 & \\
\hline 2/3 Point & 100.00 & \\
\hline Average & 100.00 & Meets Spec \\
\hline Standard Deviation & 0 & Meets Spec \\
\hline
\end{tabular}

\begin{tabular}{|c|c|c|}
\hline Height & $\mathrm{mm}$ to the nearest 0.1 & \\
\hline 0 Point & 150.00 & \\
\hline 1/4 Point & 150.00 & \\
\hline 1/2 Point & 150.00 & \\
\hline 3/4 Point & 150.00 & \\
\hline Average & 150.00 & Meets Spec \\
\hline Standard Deviation & 0 & Meets Spec \\
\hline
\end{tabular}

\begin{tabular}{|c|l|l|}
\cline { 2 - 3 } \multicolumn{1}{c|}{} & Accept & Reject \\
\hline End Perpendicularity within $1.0 \mathrm{~mm}$ & & \\
\hline End Planeness witin $0.5 \mathrm{~mm}$ & & \\
\hline
\end{tabular}

Figure 14-AMPT Test Specimen Information Sheet 


\section{Appendix B - Initial AMPT Setup}

\section{AMPT Set-up}

Upon arrival of the Instrotek technician for final setup of the machine, additional materials were acquired for final setup. These items mainly consisted of materials needed to supply the machine with the required compressed air supply, such as air hose and an air dryer. In addition, due to location constrains, a temporary extension cord was fabricated to supply the machine with power while additional room could be made and details regarding power supply could be worked out.

Setup and calibration of the AMPT was completed by an Instrotek technician, which was then followed by training on how to properly use the machine. This training covered operation of the machine for dynamic modulus and flow number.

\section{Specimen Preparation Equipment}

Similar to the AMPT, the curricular saw, shown in Figure 15, and corer, shown in Figure 16, were set up and prepared for use prior to the training session with the technician. Several problems were encountered during the initial set up, mainly pertaining to the saw. The saw was set up to run on 115 Volts (V) and 25 Amps (A) from the factory, however no suitable outlet for this style plug could be found. After switching the plug and trying to turn the machine on, the breaker was unable to maintain the amperage needed to start the saw and keep it running. This eventually led to plug on the saw being switched over to a $230 \mathrm{~V}$ plug and converting the machine to run off of this power supply via the switch in on the back of the machine. 


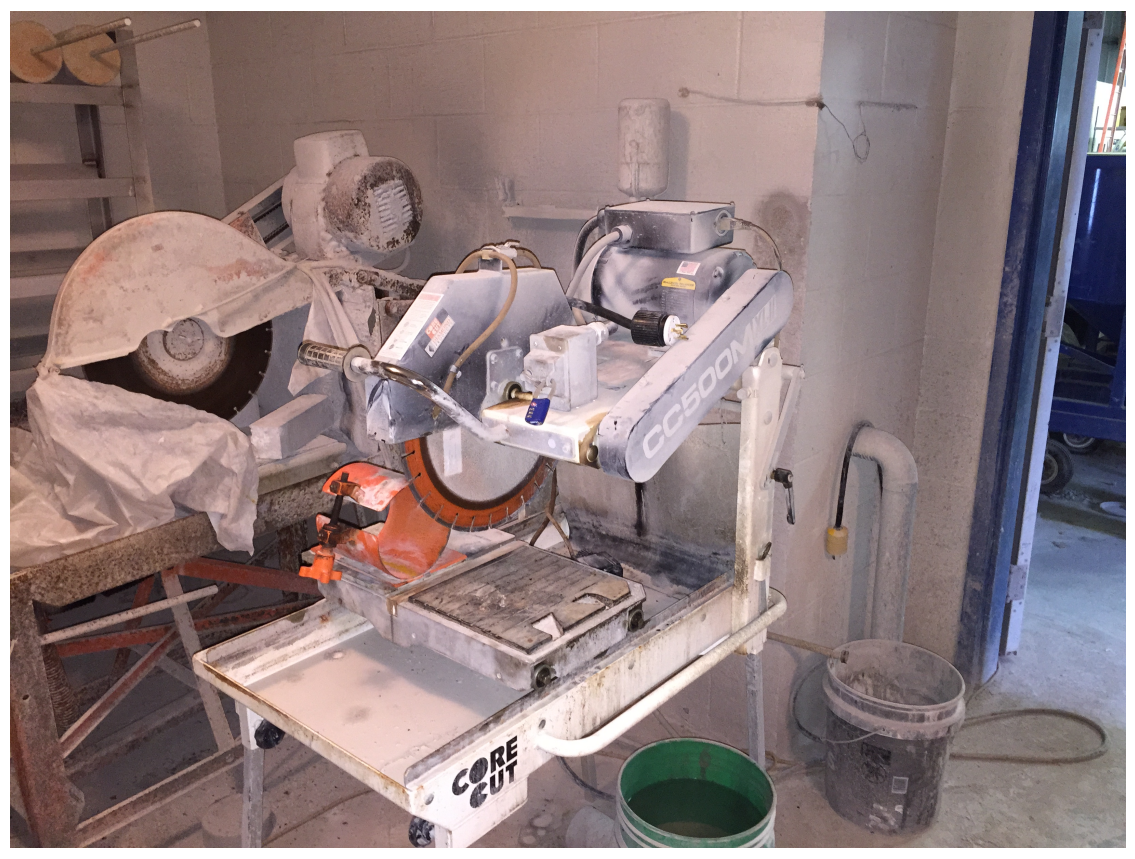

Figure 15-Circular Saw

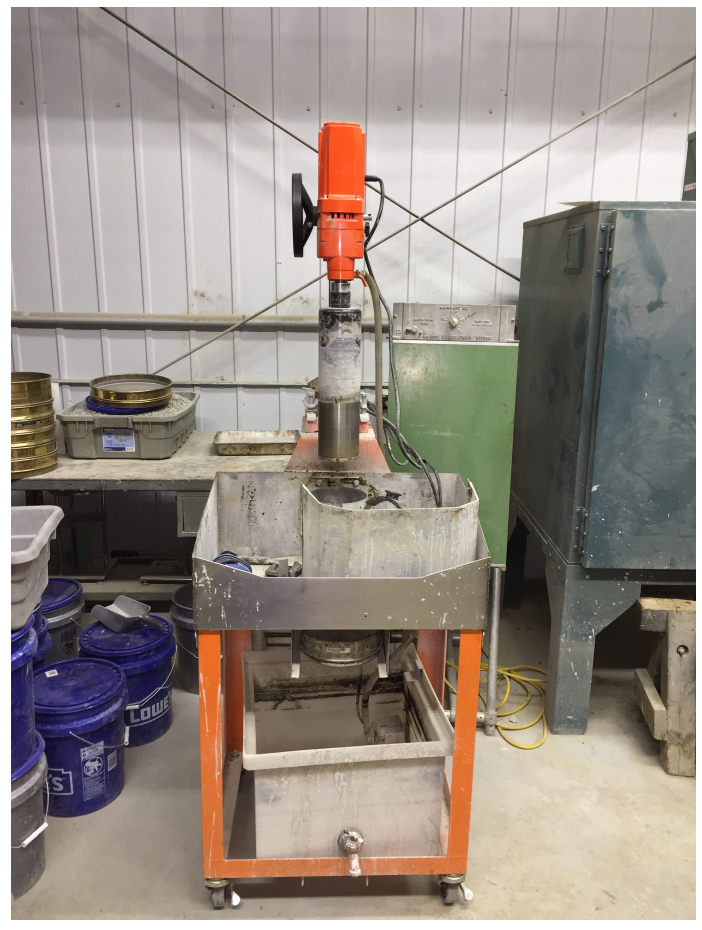

Figure 16-Core Drill

Initial setup of the corer went somewhat smoother, however issues were also encountered while coring the second specimen. The first sample cored did not experience 
any problem, however upon completion of the second core the specimen became wedged in the core bit. Since this was only a specimen that was going to be used for training, the goal was to simply remove the specimen from the bit. Much coaxing was needed, causing severe damage to the specimen, however this provided valuable experience for future reference. Upon inspection of the specimen, it was determined that the mixture had a relatively high binder content and the specimen was cored to quickly. This led to some of the binder being caught between the bit and sample.

Additionally, problems were encountered with chipping on the ends of the specimens during the sawing process. As evidenced by Figure 17, some of these chips were significant in size, thus potentially affecting the outcome of test results. The chipping did seem to be a problem that varied significantly, with larger NMAS mixtures having larger chips than the smaller NMAS mixtures.

After brainstorming potential ways to eliminate or minimize the chipping, several ideas were developed. First was taping the portion of the specimen that was being cut in order to help hold the specimen together. This worked to an extent, however pieces that were chipped during the sawing would then be peeled off during the removal of the tape. The second solution was to simply change the order in which the specimens were made, i.e. sawing first followed by coring to eliminate the chipping. This second solution had the most impact on ensuring minimal chipping was occurring. As added protection the samples were placed on an acrylic block to provide more resistance to the downward force of the corer, and to prevent the specimen from falling after the coring was completed. 


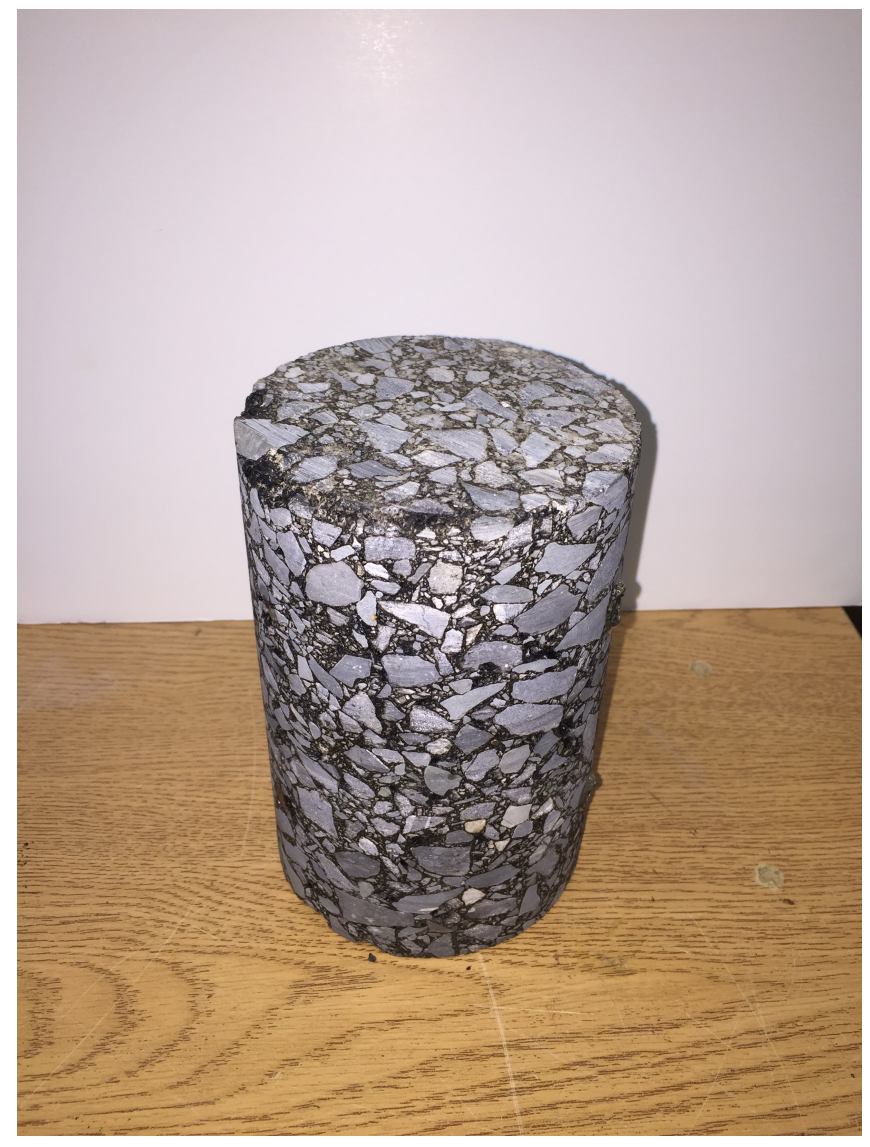

Figure 17-Test Specimen with Chipped End

Once the process for manufacturing the specimens was established, it was necessary to check them for acceptance and prepare suitable specimens for testing. A specimen data sheet, shown in Appendix A, was developed. When entered into excel, this sheet will calculate all necessary information to ensure that the test specimen meets the requirements, which are listed in

Table 23, along with the Air Void content of the specimen. The sheet will also alert a user if the specimen does not fall within any of the specifications, however the end plainness and perpendicularity must be entered manually as these are physical checks that cannot be calculated. 
Table 23-Test Specimen Dimensional Tolerances

\begin{tabular}{|c|c|}
\hline Item & Specification \\
\hline Average Diameter & 98 to $104 \mathrm{~mm}$ \\
\hline Standard Deviation of Diameter & $\leq 0.5 \mathrm{~mm}$ \\
\hline Average Height & 147.5 to $152.5 \mathrm{~mm}$ \\
\hline End Flatness & $\leq 0.5 \mathrm{~mm}$ \\
\hline End Perpendicularity & $\leq 0.1 \mathrm{~mm}$ \\
\hline
\end{tabular}

\section{Specimen Conditioning}

In accordance with AASHTO TP 79, prior to testing for dynamic modulus the test specimens must be placed in a conditioning chamber, which is capable of maintaining the desired temperature to within $0.5^{\circ} \mathrm{C}$, overnight. While the AMPT environmental chamber is capable of maintaining this temperature requirement, the time required for the specimen to equilibrate to the testing temperature makes this option time prohibitive as the machine is tied up and not available to test. To solve this problem, an inquiry was made to Instrotek Inc. about purchasing one of the conditioning chambers they sell, however at $\$ 4,500$ it was decided that other options would be investigated first. Upon this further investigation, a temperature-controlling unit was found, which was purchased and determined to be capable of maintaining the required temperatures. Furthermore, in order to accommodate a larger number of specimens, and expedite the testing process, a larger refrigerator was purchased. All together this setup, shown in Figure 18, only cost roughly $\$ 300$ and will maintain the temperatures for testing at $4^{\circ} \mathrm{C}$ and $20^{\circ} \mathrm{C}$. 


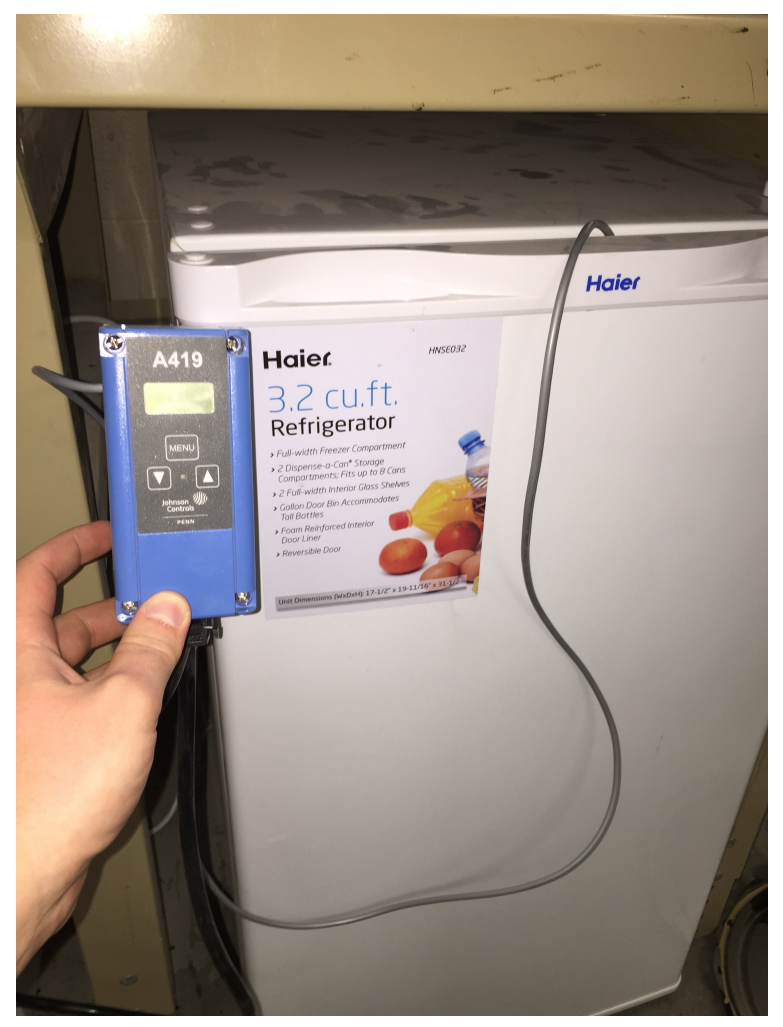

Figure 18-Temperature Control Unit and Refrigerator

For maintaining the high testing temperature, which will vary based on the binder grade being used, the Yamato force draft ovens were found to hold the temperature within the desired range. Verification was done to ensure that the specimens, and not just the chambers, were being maintained at the proper testing temperatures through inserting a thermometer probe into a specimen, as shown in Figure 19. In Figure 20, the progression of a sample to reach one of the testing temperatures, specifically $4^{\circ} \mathrm{C}$ for dynamic modulus testing, can be seen. Temperatures were recorded at 15-minute intervals to capture the gradual equilibrium, and to ensure that the required time in the chambers was adequate, which was proven. 


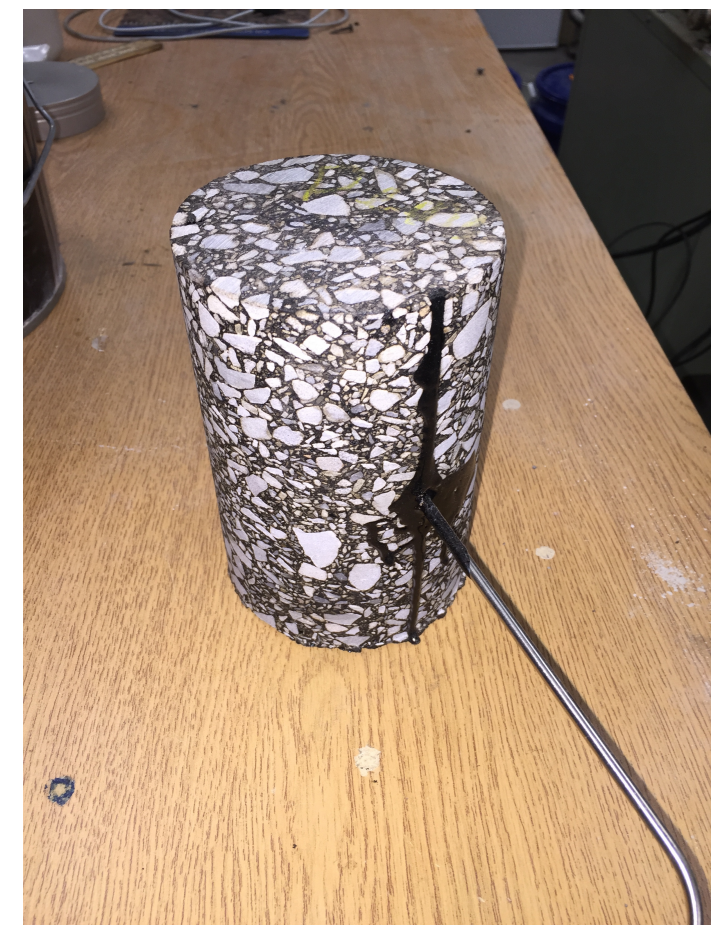

Figure 19-Test Specimen with Thermometer Probe Inserted

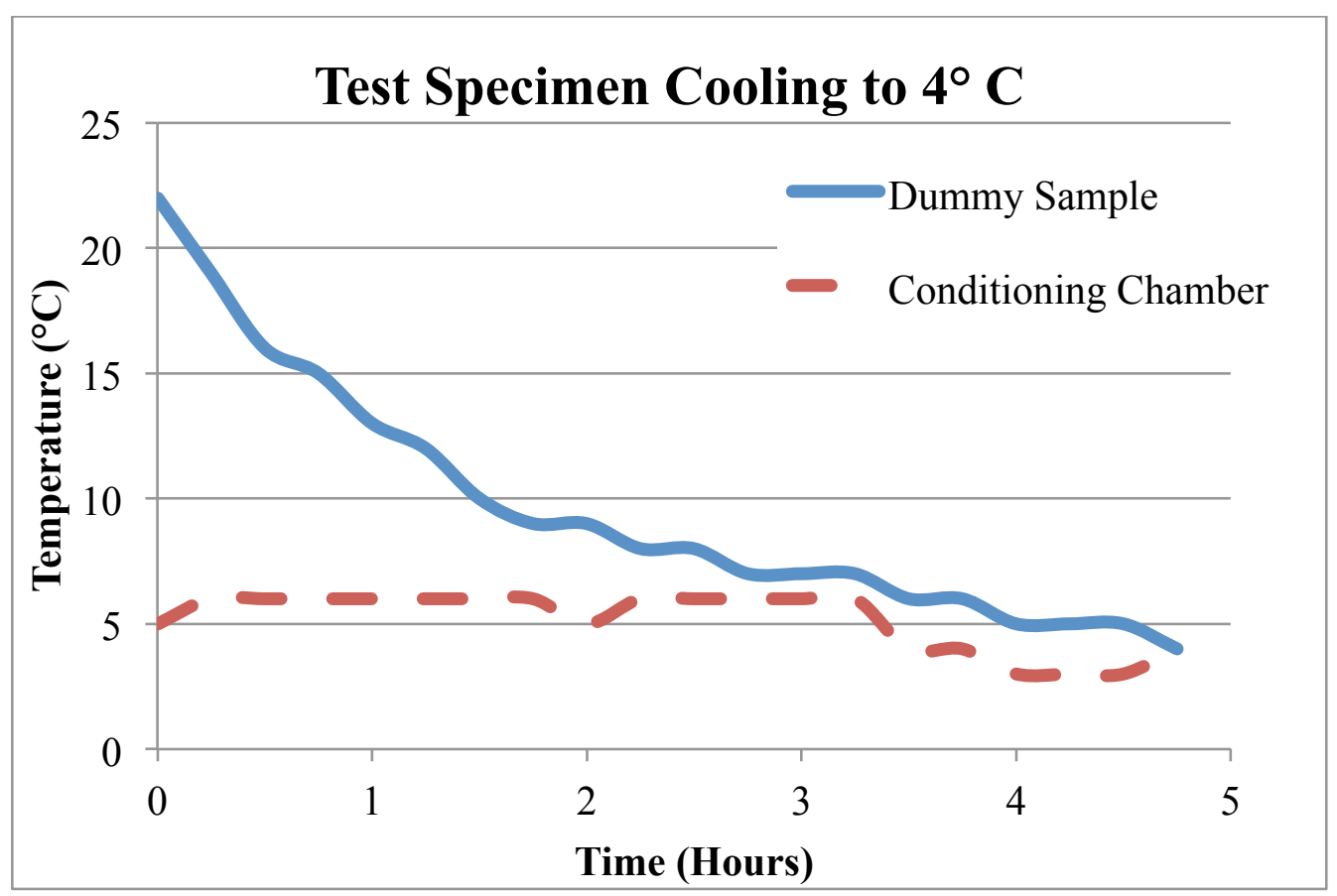

Figure 20-Specimen Cooling Graph 


\section{Appendix C - Dynamic Modulus Test Data}

Table 24-Dynamic Modulus Test Data

\begin{tabular}{|c|c|c|c|c|}
\hline Sample & $\begin{array}{c}\text { Temperature } \\
\left({ }^{\circ} \mathrm{C}\right) \\
\end{array}$ & $\begin{array}{c}\text { Frequency } \\
(\mathrm{Hz})\end{array}$ & $\begin{array}{c}\text { Dynamic Modulus } \\
(\mathrm{ksi})\end{array}$ & $\begin{array}{c}\text { Phase Angle } \\
\text { (Degrees) }\end{array}$ \\
\hline 1 & 4 & 0.1 & 842.6 & 19.83 \\
\hline 1 & 4 & 1 & 1269 & 14.88 \\
\hline 1 & 4 & 10 & 1725 & 11.27 \\
\hline 1 & 20 & 0.1 & 215.6 & 31.75 \\
\hline 1 & 20 & 1 & 447 & 27.69 \\
\hline 1 & 20 & 10 & 810.1 & 21.99 \\
\hline 1 & 45 & 0.01 & 13.8 & 21.89 \\
\hline 1 & 45 & 0.1 & 22.1 & 26.49 \\
\hline 1 & 45 & 1 & 45.2 & 31.71 \\
\hline 1 & 45 & 10 & 109.4 & 35.78 \\
\hline 2 & 4 & 0.1 & 1076 & 17.92 \\
\hline 2 & 4 & 1 & 1522 & 13.53 \\
\hline 2 & 4 & 10 & 1978 & 10.5 \\
\hline 2 & 20 & 0.1 & 323.1 & 29.08 \\
\hline 2 & 20 & 1 & 627.5 & 25.16 \\
\hline 2 & 20 & 10 & 1064 & 19.92 \\
\hline 2 & 45 & 0.01 & 23 & 21.77 \\
\hline 2 & 45 & 0.1 & 34.5 & 25.89 \\
\hline 2 & 45 & 1 & 67.2 & 30.58 \\
\hline 2 & 45 & 10 & 155.6 & 34.28 \\
\hline 3 & 4 & 0.1 & 1069 & 18.27 \\
\hline 3 & 4 & 1 & 1549 & 13.55 \\
\hline 3 & 4 & 10 & 2055 & 10.23 \\
\hline 3 & 20 & 0.1 & 298.2 & 30.14 \\
\hline 3 & 20 & 1 & 591.2 & 25.84 \\
\hline 3 & 20 & 10 & 1020 & 20.23 \\
\hline 3 & 40 & 0.01 & 24 & 23.71 \\
\hline 3 & 40 & 0.1 & 42.6 & 28.49 \\
\hline 3 & 40 & 1 & 94.1 & 32.71 \\
\hline 3 & 40 & 10 & 224.9 & 34.51 \\
\hline 4 & 4 & 0.1 & 775.4 & 20.83 \\
\hline 4 & 4 & 1 & 1179 & 15.85 \\
\hline 4 & 4 & 10 & 1633 & 11.89 \\
\hline 4 & 20 & 0.1 & 225.1 & 31.16 \\
\hline 4 & 20 & 1 & 462.8 & 27.38 \\
\hline 4 & 20 & 10 & 831.9 & 21.79 \\
\hline
\end{tabular}




\begin{tabular}{|c|c|c|c|c|}
\hline Sample & $\begin{array}{c}\text { Temperature } \\
\left({ }^{\circ} \mathrm{C}\right)\end{array}$ & $\begin{array}{c}\text { Frequency } \\
(\mathrm{Hz})\end{array}$ & $\begin{array}{l}\text { Dynamic Modulus } \\
\text { (ksi) }\end{array}$ & $\begin{array}{c}\text { Phase Angle } \\
\text { (Degrees) }\end{array}$ \\
\hline 4 & 40 & 0.01 & 20.1 & 23.32 \\
\hline 4 & 40 & 0.1 & 33.4 & 28.1 \\
\hline 4 & 40 & 1 & 71.1 & 33 \\
\hline 4 & 40 & 10 & 171.8 & 35.47 \\
\hline 5 & 4 & 0.1 & 1014 & 19.65 \\
\hline 5 & 4 & 1 & 1513 & 14.59 \\
\hline 5 & 4 & 10 & 2058 & 10.84 \\
\hline 5 & 20 & 0.1 & 313.2 & 30.68 \\
\hline 5 & 20 & 1 & 619.4 & 26.15 \\
\hline 5 & 20 & 10 & 1078 & 20.32 \\
\hline 5 & 40 & 0.01 & 20.7 & 24.71 \\
\hline 5 & 40 & 0.1 & 42.9 & 29.21 \\
\hline 5 & 40 & 1 & 102.8 & 33.25 \\
\hline 5 & 40 & 10 & 243.9 & 34.87 \\
\hline 6 & 4 & 0.1 & 691.9 & 22.58 \\
\hline 6 & 4 & 1 & 1084 & 17.07 \\
\hline 6 & 4 & 10 & 1545 & 12.84 \\
\hline 6 & 20 & 0.1 & 205.1 & 32.81 \\
\hline 6 & 20 & 1 & 431.1 & 28.63 \\
\hline 6 & 20 & 10 & 788.8 & 22.61 \\
\hline 6 & 40 & 0.01 & 15.4 & 24.05 \\
\hline 6 & 40 & $\begin{array}{l}0.1 \\
\end{array}$ & 27.8 & 29.49 \\
\hline 6 & 40 & 1 & 64 & 34.47 \\
\hline 6 & 40 & 10 & 159.9 & 36.89 \\
\hline 7 & 4 & 0.1 & 891.4 & 18.81 \\
\hline 7 & 4 & 1 & 1326 & 14.46 \\
\hline 7 & 4 & 10 & 1824 & 11.02 \\
\hline 7 & 20 & 0.1 & 292.2 & 28.85 \\
\hline 7 & 20 & 1 & 562 & 24.7 \\
\hline 7 & 20 & 10 & 951.5 & 19.66 \\
\hline 7 & 45 & 0.01 & 21.1 & 22.67 \\
\hline 7 & 45 & 0.1 & 32.8 & 26.88 \\
\hline 7 & 45 & 1 & 63.1 & 31.29 \\
\hline 7 & 45 & 10 & 143.7 & 34.25 \\
\hline 8 & 4 & 0.1 & 1050 & 18.36 \\
\hline 8 & 4 & 1 & 1532 & 14.01 \\
\hline 8 & 4 & 10 & 2055 & 10.67 \\
\hline 8 & 20 & 0.1 & 338.5 & 28.37 \\
\hline 8 & 20 & 1 & 643.3 & 24.41 \\
\hline 8 & 20 & 10 & 1073 & 19.34 \\
\hline 8 & 45 & 0.01 & 23.8 & 22.08 \\
\hline
\end{tabular}




\begin{tabular}{|c|c|c|c|c|}
\hline Sample & $\begin{array}{c}\text { Temperature } \\
\left({ }^{\circ} \mathrm{C}\right)\end{array}$ & $\begin{array}{c}\text { Frequency } \\
(\mathrm{Hz})\end{array}$ & $\begin{array}{l}\text { Dynamic Modulus } \\
\text { (ksi) }\end{array}$ & $\begin{array}{c}\text { Phase Angle } \\
\text { (Degrees) }\end{array}$ \\
\hline 8 & 45 & 0.1 & 36.1 & 26.51 \\
\hline 8 & 45 & 1 & 69.2 & 31.24 \\
\hline 8 & 45 & 10 & 156.6 & 34.65 \\
\hline 9 & 4 & 0.1 & 711.6 & 21.74 \\
\hline 9 & 4 & 1 & 1099 & 16.76 \\
\hline 9 & 4 & 10 & 1558 & 12.69 \\
\hline 9 & 20 & 0.1 & 215.2 & 30.63 \\
\hline 9 & 20 & 1 & 441.8 & 27.37 \\
\hline 9 & 20 & 10 & 796 & 21.97 \\
\hline 9 & 45 & 0.01 & 19 & 18.89 \\
\hline 9 & 45 & 0.1 & 27.9 & 23.81 \\
\hline 9 & 45 & 1 & 52.4 & 29.58 \\
\hline 9 & 45 & 10 & 120.5 & 34.21 \\
\hline 10 & 4 & 0.1 & 835.9 & 21.03 \\
\hline 10 & 4 & 1 & 1267 & 16.03 \\
\hline 10 & 4 & 10 & 1769 & 11.99 \\
\hline 10 & 20 & 0.1 & 256.2 & 30.82 \\
\hline 10 & 20 & 1 & 521.4 & 27.02 \\
\hline 10 & 20 & 10 & 921.5 & 21.43 \\
\hline 10 & 40 & 0.01 & 21.5 & 23.34 \\
\hline 10 & 40 & 0.1 & 38.9 & 28.41 \\
\hline 10 & 40 & 1 & 87.3 & 32.78 \\
\hline 10 & 40 & 10 & 210.7 & 34.93 \\
\hline 11 & 4 & 0.1 & 711.1 & 21.57 \\
\hline 11 & 4 & 1 & 1098 & 16.61 \\
\hline 11 & 4 & 10 & 1548 & 12.55 \\
\hline 11 & 20 & 0.1 & 237.1 & 30.66 \\
\hline 11 & 20 & 1 & 480.1 & 26.58 \\
\hline 11 & 20 & 10 & 847.8 & 21.07 \\
\hline 11 & 45 & 0.01 & 15.5 & 21.82 \\
\hline 11 & 45 & 0.1 & 24.7 & 26.48 \\
\hline 11 & 45 & 1 & 49.5 & 31.5 \\
\hline 11 & 45 & 10 & 117.9 & 35.19 \\
\hline 12 & 4 & 0.1 & 805.2 & 19.05 \\
\hline 12 & 4 & 1 & 1178 & 14.21 \\
\hline 12 & 4 & 10 & 1574 & 10.85 \\
\hline 12 & 20 & 0.1 & 230.3 & 31.82 \\
\hline 12 & 20 & 1 & 456.8 & 26.76 \\
\hline 12 & 20 & 10 & 795.9 & 20.77 \\
\hline 12 & 40 & 0.01 & 17.3 & 24.82 \\
\hline 12 & 40 & 0.1 & 35.8 & 30.67 \\
\hline
\end{tabular}




\begin{tabular}{|c|c|c|c|c|}
\hline Sample & $\begin{array}{c}\text { Temperature } \\
\left({ }^{\circ} \mathrm{C}\right)\end{array}$ & $\begin{array}{c}\text { Frequency } \\
(\mathrm{Hz})\end{array}$ & $\begin{array}{l}\text { Dynamic Modulus } \\
\text { (ksi) }\end{array}$ & $\begin{array}{c}\text { Phase Angle } \\
\text { (Degrees) }\end{array}$ \\
\hline 12 & 40 & 1 & 83.8 & 34.61 \\
\hline 12 & 40 & 10 & 194.7 & 35.2 \\
\hline 13 & 4 & 0.1 & 846.2 & 19.98 \\
\hline 13 & 4 & 1 & 1269 & 14.96 \\
\hline 13 & 4 & 10 & 1735 & 11.36 \\
\hline 13 & 20 & 0.1 & 272.7 & 30.89 \\
\hline 13 & 20 & 1 & 538.4 & 25.92 \\
\hline 13 & 20 & 10 & 933.3 & 20.13 \\
\hline 13 & 40 & 0.01 & 19.8 & 23.71 \\
\hline 13 & 40 & 0.1 & 40.5 & 29.45 \\
\hline 13 & 40 & 1 & 93.7 & 34.05 \\
\hline 13 & 40 & 10 & 216.4 & 34.98 \\
\hline 14 & 4 & 0.1 & 948.2 & 18.18 \\
\hline 14 & 4 & 1 & 1381 & 13.47 \\
\hline 14 & 4 & 10 & 1822 & 10.25 \\
\hline 14 & 20 & 0.1 & 273.7 & 30.5 \\
\hline 14 & 20 & 1 & 537.8 & 25.71 \\
\hline 14 & 20 & 10 & 922.1 & 19.96 \\
\hline 14 & 40 & 0.01 & 18.3 & 25.48 \\
\hline 14 & 40 & 0.1 & 37.3 & 29.93 \\
\hline 14 & 40 & 1 & 86.3 & 33.79 \\
\hline 14 & 40 & 10 & 202.1 & 34.88 \\
\hline 15 & 4 & 0.1 & 978 & 18.54 \\
\hline 15 & 4 & 1 & 1429 & 13.8 \\
\hline 15 & 4 & 10 & 1906 & 10.43 \\
\hline 15 & 20 & 0.1 & 309.8 & 29.93 \\
\hline 15 & 20 & 1 & 603.8 & 25.05 \\
\hline 15 & 20 & 10 & 1024 & 19.36 \\
\hline 15 & 40 & 0.01 & 20.3 & 24.78 \\
\hline 15 & 40 & 0.1 & 41.3 & 29.37 \\
\hline 15 & 40 & 1 & 97.3 & 33.19 \\
\hline 15 & 40 & 10 & 229.5 & 34.33 \\
\hline 16 & 4 & 0.1 & 878.8 & 19.6 \\
\hline 16 & 4 & 1 & 1307 & 14.6 \\
\hline 16 & 4 & 10 & 1764 & 10.96 \\
\hline 16 & 20 & 0.1 & 257.7 & 30.88 \\
\hline 16 & 20 & 1 & 528.2 & 26.5 \\
\hline 16 & 20 & 10 & 918.3 & 20.64 \\
\hline 16 & 40 & 0.01 & 17.9 & 23.53 \\
\hline 16 & 40 & 0.1 & 31.8 & 28.43 \\
\hline 16 & 40 & 1 & 70.3 & 32.85 \\
\hline
\end{tabular}




\begin{tabular}{|c|c|c|c|c|}
\hline Sample & $\begin{array}{c}\text { Temperature } \\
\left({ }^{\circ} \mathrm{C}\right)\end{array}$ & $\begin{array}{c}\text { Frequency } \\
(\mathrm{Hz})\end{array}$ & $\begin{array}{l}\text { Dynamic Modulus } \\
\text { (ksi) }\end{array}$ & $\begin{array}{c}\text { Phase Angle } \\
\text { (Degrees) }\end{array}$ \\
\hline 16 & 40 & 10 & 171.4 & 35.43 \\
\hline 17 & 4 & 0.1 & 1017 & 17.11 \\
\hline 17 & 4 & 1 & 1445 & 13 \\
\hline 17 & 4 & 10 & 1899 & 10.06 \\
\hline 17 & 20 & 0.1 & 353 & 27.33 \\
\hline 17 & 20 & 1 & 654.4 & 23.22 \\
\hline 17 & 20 & 10 & 1068 & 18.37 \\
\hline 17 & 45 & 0.01 & 26.8 & 21.92 \\
\hline 17 & 45 & 0.1 & 41.6 & 26.01 \\
\hline 17 & 45 & 1 & 79.2 & 30.09 \\
\hline 17 & 45 & 10 & 174.6 & 32.94 \\
\hline 18 & 4 & 0.1 & 840.4 & 18.67 \\
\hline 18 & 4 & 1 & 1227 & 14.33 \\
\hline 18 & 4 & 10 & 1641 & 11.02 \\
\hline 18 & 20 & 0.1 & 270 & 28.57 \\
\hline 18 & 20 & 1 & 521.7 & 24.79 \\
\hline 18 & 20 & 10 & 883.2 & 19.87 \\
\hline 18 & 45 & 0.01 & 21.8 & 22.27 \\
\hline 18 & 45 & 0.1 & 32.5 & 26.26 \\
\hline 18 & 45 & 1 & 60.4 & 30.61 \\
\hline 18 & 45 & 10 & 134.3 & 33.74 \\
\hline 19 & 4 & 0.1 & 808.7 & 19.06 \\
\hline 19 & 4 & 1 & 1189 & 14.68 \\
\hline 19 & 4 & 10 & 1611 & 11.41 \\
\hline 19 & 20 & 0.1 & 245.4 & 29.61 \\
\hline 19 & 20 & 1 & 485.7 & 25.65 \\
\hline 19 & 45 & 0.01 & 19.2 & 20.67 \\
\hline 19 & 45 & 0.1 & 29.5 & 24.94 \\
\hline 19 & 45 & 1 & 56.5 & 29.34 \\
\hline 19 & 45 & 10 & 128.1 & 32.95 \\
\hline 20 & 4 & 0.1 & 983.1 & 18.71 \\
\hline 20 & 4 & 1 & 1442 & 14.13 \\
\hline 20 & 4 & 10 & 1945 & 10.72 \\
\hline 20 & 20 & 0.1 & 329.4 & 28.73 \\
\hline 20 & 20 & 1 & 627.8 & 24.63 \\
\hline 20 & 20 & 10 & 1059 & 19.39 \\
\hline 20 & 40 & 0.01 & 24.2 & 26.19 \\
\hline 20 & 40 & 0.1 & 49.6 & 30.38 \\
\hline 20 & 40 & 1 & 113.6 & 33.54 \\
\hline 20 & 40 & 10 & 262 & 33.94 \\
\hline 21 & 4 & 0.1 & 841.7 & 20.4 \\
\hline
\end{tabular}




\begin{tabular}{|c|c|c|c|c|}
\hline Sample & $\begin{array}{c}\text { Temperature } \\
\left({ }^{\circ} \mathrm{C}\right)\end{array}$ & $\begin{array}{c}\text { Frequency } \\
(\mathrm{Hz})\end{array}$ & $\begin{array}{c}\text { Dynamic Modulus } \\
(\mathrm{ksi})\end{array}$ & $\begin{array}{c}\text { Phase Angle } \\
(\text { Degrees })\end{array}$ \\
\hline 21 & 4 & 1 & 1262 & 15.41 \\
\hline 21 & 4 & 10 & 1726 & 11.57 \\
\hline 21 & 20 & 0.1 & 267.6 & 30.74 \\
\hline 21 & 20 & 1 & 535.4 & 26.39 \\
\hline 21 & 20 & 10 & 934.1 & 20.67 \\
\hline 21 & 40 & 0.01 & 21.8 & 23.82 \\
\hline 21 & 40 & 0.1 & 38.8 & 28.92 \\
\hline 21 & 40 & 1 & 86.4 & 33.18 \\
\hline 21 & 40 & 10 & 206.8 & 34.95 \\
\hline
\end{tabular}


Table 25-Dynamic Modulus Test Specimen Data

\begin{tabular}{|c|l|c|c|c|c|}
\hline Sample & \multicolumn{1}{|c|}{ Binder } & NMAS & VTM & VMA & VFA \\
\hline 1 & PG 70-22 PM (65) & 9.5 & 7.2 & 19.4 & 62.7 \\
\hline 2 & PG 76-22 PM & 12.5 & 6.8 & 16.9 & 59.8 \\
\hline 3 & PG 70-22 PM & 12.5 & 7.4 & 17.9 & 58.6 \\
\hline 4 & PG 70-22 PM (80) & 9.5 & 7.2 & 19.4 & 62.8 \\
\hline 5 & PG 70-22 & 12.5 & 7.0 & 17.7 & 60.6 \\
\hline 6 & PG 70-22 PM (80) & 9.5 & 7.2 & 19.4 & 62.7 \\
\hline 7 & PG 76-22 PM & 9.5 & 7.1 & 18.9 & 62.5 \\
\hline 8 & PG 76-22 PM & 12.5 & 6.5 & 16.6 & 61.1 \\
\hline 9 & PG 70-22 PM (65) & 9.5 & 6.9 & 19.1 & 63.7 \\
\hline 10 & PG 70-22 PM & 12.5 & 7.2 & 17.7 & 59.4 \\
\hline 11 & PG 70-22 PM (65) & 9.5 & 6.9 & 19.1 & 63.8 \\
\hline 12 & PG 70-22 & 9.5 & 7.2 & 19.1 & 62.3 \\
\hline 13 & PG 70-22 & 9.5 & 7.1 & 18.9 & 62.7 \\
\hline 14 & PG 70-22 & 9.5 & 7.0 & 18.9 & 62.9 \\
\hline 15 & PG 70-22 & 12.5 & 6.8 & 17.5 & 61.2 \\
\hline 16 & PG 70-22 PM (80) & 9.5 & 6.9 & 19.1 & 63.7 \\
\hline 17 & PG 76-22 PM & 12.5 & 7.4 & 17.5 & 57.4 \\
\hline 18 & PG 76-22 PM & 9.5 & 6.9 & 18.8 & 63.1 \\
\hline 19 & PG 76-22 PM & 9.5 & 7.0 & 18.9 & 62.8 \\
\hline 20 & PG 70-22 & 12.5 & 6.7 & 17.5 & 61.5 \\
\hline 21 & PG 70-22 PM & 12.5 & 7.0 & 17.6 & 60.0 \\
\hline & & & & & \\
\hline
\end{tabular}




\section{Appendix D - Flow Number Test Data}

Table 26-Flow Number Test Data

\begin{tabular}{|c|c|c|c|c|c|c|c|c|}
\hline Sample & Binder & NMAS & $\begin{array}{l}\text { Oven } \\
\text { Ageing } \\
\text { Time }\end{array}$ & $\begin{array}{c}\text { Dynamic } \\
\text { Modulus } \\
\text { Testing }\end{array}$ & VTM & $\begin{array}{c}\mathrm{FN} \\
(\mathrm{n}=1)\end{array}$ & $\begin{array}{c}\mathrm{FN} \\
(\mathrm{n}=20)\end{array}$ & $\begin{array}{c}\text { FN } \\
\text { Index }\end{array}$ \\
\hline 1 & PG 70-22 & 12.5 & 2 & Yes & 5.5 & 1131 & 985 & 21.6 \\
\hline 2 & $\begin{array}{c}\text { PG 70-22 PM } \\
(80)\end{array}$ & 12.5 & 2 & Yes & 5.3 & 1731 & 1714 & 14.2 \\
\hline 3 & PG 76-22 PM & 9.5 & 2 & No & 5.6 & 2151 & 2474 & 10.3 \\
\hline 4 & $\begin{array}{c}\text { PG 70-22 PM } \\
(80)\end{array}$ & 9.5 & 2 & Yes & 5.6 & 984 & 1121 & 23.3 \\
\hline 5 & $\begin{array}{c}\text { PG 70-22 PM } \\
(65)\end{array}$ & 9.5 & 2 & No & 5.3 & 1533 & 1571 & 15.8 \\
\hline 6 & $\begin{array}{c}\text { PG 70-22 PM } \\
(65)\end{array}$ & 9.5 & 2 & No & 5.4 & 1133 & 1277 & 21.2 \\
\hline 7 & $\begin{array}{c}\text { PG 70-22 PM } \\
(65)\end{array}$ & 12.5 & 4 & No & 4.9 & 4887 & 4031 & 5.5 \\
\hline 9 & $\begin{array}{c}\text { PG 70-22 PM } \\
(65)\end{array}$ & 9.5 & 4 & No & 4.9 & 2409 & 4056 & 7.2 \\
\hline 10 & $\begin{array}{c}\text { PG 70-22 PM } \\
(80)\end{array}$ & 9.5 & 4 & No & 5.8 & 2102 & 2670 & 13.0 \\
\hline 11 & PG 70-22 & 9.5 & 2 & No & 6.2 & 392 & 427 & 50.5 \\
\hline 12 & $\begin{array}{c}\text { PG 70-22 PM } \\
(65)\end{array}$ & 12.5 & 2 & Yes & 5.5 & 1478 & 1722 & 14.5 \\
\hline 13 & $\begin{array}{c}\text { PG 70-22 PM } \\
(80)\end{array}$ & 9.5 & 4 & No & 5.7 & 3677 & 3773 & 7.2 \\
\hline 14 & PG 70-22 & 12.5 & 2 & Yes & 5.3 & 784 & 789 & 26.2 \\
\hline 15 & PG 76-22 PM & 9.5 & 2 & Yes & 5.6 & 9194 & 5919 & 3.2 \\
\hline 16 & PG 76-22 PM & 9.5 & 2 & Yes & 5.5 & 4156 & 3560 & 5.9 \\
\hline 17 & $\begin{array}{c}\text { PG 70-22 PM } \\
(80)\end{array}$ & 9.5 & 2 & No & 5.9 & 1249 & 1081 & 22.5 \\
\hline 18 & $\begin{array}{c}\text { PG 70-22 PM } \\
(80)\end{array}$ & 12.5 & 2 & Yes & 4.6 & 2446 & 2313 & 9.5 \\
\hline 19 & $\begin{array}{c}\text { PG 70-22 PM } \\
(65)\end{array}$ & 12.5 & 2 & Yes & 4.9 & 2493 & 2041 & 9.9 \\
\hline 20 & PG 76-22 PM & 12.5 & 4 & No & 5.4 & 9125 & 7484 & 3.2 \\
\hline 21 & $\begin{array}{c}\text { PG 70-22 PM } \\
(65)\end{array}$ & 12.5 & 4 & No & 4.9 & 3164 & 4857 & 6.6 \\
\hline 22 & $\begin{array}{c}\text { PG 70-22 PM } \\
(80)\end{array}$ & 12.5 & 2 & No & 5.4 & 1616 & 1599 & 16.2 \\
\hline 23 & $\begin{array}{c}\text { PG 70-22 PM } \\
(65)\end{array}$ & 12.5 & 4 & No & 4.5 & 3213 & 4233 & 6.5 \\
\hline & & & & & & & & \\
\hline
\end{tabular}




\begin{tabular}{|c|c|c|c|c|c|c|c|c|}
\hline Sample & Binder & NMAS & $\begin{array}{c}\text { Oven } \\
\text { Ageing } \\
\text { Time }\end{array}$ & $\begin{array}{c}\text { Dynamic } \\
\text { Modulus } \\
\text { Testing }\end{array}$ & VTM & $\begin{array}{c}\mathrm{FN} \\
(\mathrm{n}=1)\end{array}$ & $\begin{array}{c}\mathrm{FN} \\
(\mathrm{n}=20)\end{array}$ & $\begin{array}{c}\mathrm{FN} \\
\text { Index }\end{array}$ \\
\hline 24 & PG 70-22 & 9.5 & 2 & Yes & 5.5 & 487 & 528 & 38.1 \\
\hline 25 & $\begin{array}{c}\text { PG 70-22 PM } \\
(80)\end{array}$ & 9.5 & 2 & No & 5.5 & 1401 & 1238 & 16.9 \\
\hline 26 & PG 70-22 & 9.5 & 2 & Yes & 5.7 & 658 & 532 & 33.7 \\
\hline 27 & PG 70-22 & 12.5 & 2 & No & 5.2 & 448 & 545 & 50.6 \\
\hline 28 & $\begin{array}{c}\text { PG 70-22 PM } \\
(80)\end{array}$ & 9.5 & 2 & Yes & 5.8 & 1048 & 1220 & 21.3 \\
\hline 29 & $\begin{array}{c}\text { PG } 70-22 \text { PM } \\
(65)\end{array}$ & 9.5 & 4 & No & 5.4 & 2840 & 2693 & 9.7 \\
\hline 30 & $\begin{array}{c}\text { PG 70-22 PM } \\
(65)\end{array}$ & 9.5 & 2 & Yes & 5.7 & 1047 & 1026 & 22.2 \\
\hline 31 & PG 70-22 & 12.5 & 2 & No & 5.4 & 655 & 683 & 32.2 \\
\hline 32 & $\begin{array}{c}\text { PG 70-22 PM } \\
(80)\end{array}$ & 9.5 & 2 & Yes & 5.5 & 1043 & 1084 & 21.9 \\
\hline 34 & $\begin{array}{c}\text { PG 70-22 PM } \\
(65)\end{array}$ & 9.5 & 2 & No & 5.3 & 1132 & 1296 & 19.5 \\
\hline 35 & $\begin{array}{c}\text { PG 70-22 PM } \\
(65)\end{array}$ & 9.5 & 2 & Yes & 5.4 & 1446 & 1075 & 17.9 \\
\hline 36 & PG 76-22 PM & 12.5 & 2 & Yes & 5.8 & 3468 & 4426 & 6.5 \\
\hline 37 & PG 70-22 & 12.5 & 2 & No & 4.9 & 592 & 599 & 35.1 \\
\hline 38 & $\begin{array}{c}\text { PG 70-22 PM } \\
(65)\end{array}$ & 12.5 & 2 & No & 4.7 & 2023 & 1860 & 11.9 \\
\hline 39 & $\begin{array}{c}\text { PG 70-22 PM } \\
(80)\end{array}$ & 9.5 & 2 & No & 6.0 & 843 & 986 & 26.7 \\
\hline 40 & PG 70-22 & 12.5 & 4 & No & 5.1 & 1265 & 1311 & 17.0 \\
\hline 41 & PG 70-22 & 9.5 & 2 & $\mathrm{No}$ & 6.3 & 417 & 463 & 47.9 \\
\hline 42 & PG 70-22 & 9.5 & 4 & No & 5.6 & 1132 & 1119 & 18.0 \\
\hline 43 & PG 70-22 & 9.5 & 4 & No & 5.6 & 855 & 1035 & 22.2 \\
\hline 44 & PG 76-22 PM & 12.5 & 2 & No & 5.3 & 2846 & 9061 & 5.8 \\
\hline 45 & PG 76-22 PM & 9.5 & 2 & Yes & 5.7 & 2525 & 2538 & 9.1 \\
\hline 46 & $\begin{array}{c}\text { PG 70-22 PM } \\
(80)\end{array}$ & 12.5 & 4 & No & 4.7 & 7715 & 5938 & 3.6 \\
\hline 47 & PG 70-22 & 9.5 & 2 & Yes & 6.1 & 477 & 532 & 39.2 \\
\hline 48 & PG 70-22 & 9.5 & 4 & No & 6.1 & 1107 & 1086 & 18.0 \\
\hline 49 & PG 70-22 & 9.5 & 2 & No & 5.9 & 514 & 550 & 37.5 \\
\hline 50 & PG 76-22 PM & 9.5 & 4 & No & 6.5 & 4738 & 5496 & 5.5 \\
\hline 51 & $\begin{array}{c}\text { PG 70-22 PM } \\
(65)\end{array}$ & 9.5 & 4 & No & 5.8 & 3133 & 3474 & 8.0 \\
\hline 52 & PG 76-22 PM & 12.5 & 2 & Yes & 5.3 & 2661 & 2596 & 8.3 \\
\hline 53 & PG 70-22 & 12.5 & 4 & No & 6.1 & 1556 & 1267 & 16.1 \\
\hline 54 & $\begin{array}{c}\text { PG 70-22 PM } \\
(80)\end{array}$ & 12.5 & 4 & No & 4.9 & 5566 & 4953 & 4.6 \\
\hline
\end{tabular}




\begin{tabular}{|c|c|c|c|c|c|c|c|c|}
\hline Sample & Binder & NMAS & $\begin{array}{c}\text { Oven } \\
\text { Ageing } \\
\text { Time }\end{array}$ & $\begin{array}{c}\text { Dynamic } \\
\text { Modulus } \\
\text { Testing }\end{array}$ & VTM & $\begin{array}{c}\text { FN } \\
(\mathrm{n}=1)\end{array}$ & $\begin{array}{c}\text { FN } \\
(\mathrm{n}=20)\end{array}$ & $\begin{array}{c}\text { FN } \\
\text { Index }\end{array}$ \\
\hline 55 & $\begin{array}{c}\text { PG 70-22 PM } \\
(80)\end{array}$ & 12.5 & 2 & Yes & 4.8 & 3052 & 3077 & 7.7 \\
\hline 56 & $\begin{array}{c}\text { PG 70-22 PM } \\
(65)\end{array}$ & 9.5 & 2 & Yes & 5.3 & 1652 & 1650 & 12.8 \\
\hline 57 & PG 76-22 PM & 12.5 & 2 & No & 5.1 & 3131 & 7329 & 5.7 \\
\hline 58 & PG 76-22 PM & 9.5 & 4 & No & 6.7 & 5807 & 5086 & 5.5 \\
\hline 59 & $\begin{array}{c}\text { PG 70-22 PM } \\
(80)\end{array}$ & 12.5 & 2 & No & 5.2 & 1765 & 1754 & 13.5 \\
\hline 60 & $\begin{array}{c}\text { PG 70-22 PM } \\
(65)\end{array}$ & 12.5 & 2 & Yes & 4.9 & 1792 & 2045 & 12.1 \\
\hline 61 & $\begin{array}{c}\text { PG 70-22 PM } \\
(80)\end{array}$ & 9.5 & 4 & No & 5.4 & 6083 & 6408 & 4.1 \\
\hline 62 & $\begin{array}{c}\text { PG 70-22 PM } \\
(65)\end{array}$ & 12.5 & 2 & No & 4.9 & 1967 & 2434 & 11.1 \\
\hline 63 & PG 76-22 PM & 9.5 & 4 & No & 6.6 & 3332 & 3589 & 7.6 \\
\hline 64 & PG 70-22 & 12.5 & 2 & Yes & 5.4 & 576 & 674 & 35.0 \\
\hline 65 & $\begin{array}{c}\text { PG 70-22 PM } \\
(65)\end{array}$ & 12.5 & 2 & No & 4.9 & 1112 & 1572 & 18.3 \\
\hline 66 & PG 76-22 PM & 12.5 & 2 & No & 7.8 & 5044 & 4687 & 5.1 \\
\hline 67 & PG 76-22 PM & 12.5 & 4 & No & 5.4 & 6224 & 8582 & 3.5 \\
\hline 68 & PG 76-22 PM & 9.5 & 2 & No & 6.3 & 3082 & 2506 & 9.4 \\
\hline 69 & PG 70-22 & 12.5 & 4 & No & 5.3 & 2728 & 3145 & 7.9 \\
\hline 71 & $\begin{array}{c}\text { PG 70-22 PM } \\
(80)\end{array}$ & 12.5 & 2 & No & 7.2 & 1117 & 1093 & 27.6 \\
\hline 72 & PG 76-22 PM & 12.5 & 2 & Yes & 5.2 & 3343 & 5114 & 6.2 \\
\hline
\end{tabular}

